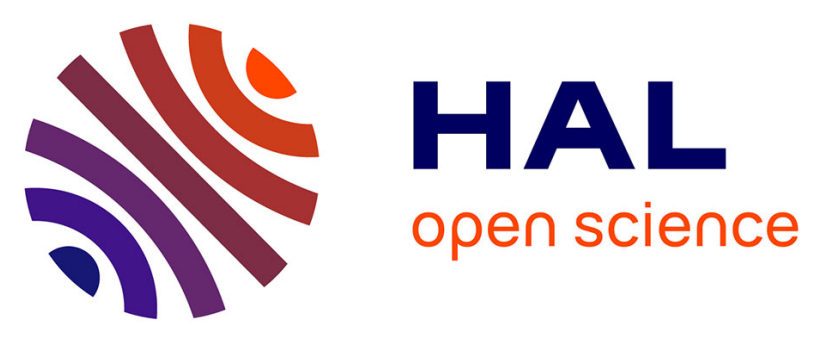

\title{
Chiral Discrete and Polymeric Uranyl Ion Complexes with $(1 R, 3 S)$-(+)-Camphorate Ligands: Counterion-Dependent Formation of a Hexanuclear Cage
} Pierre Thuéry, Youssef Atoini, Jack Harrowfield

\section{- To cite this version:}

Pierre Thuéry, Youssef Atoini, Jack Harrowfield. Chiral Discrete and Polymeric Uranyl Ion Complexes with $(1 R, 3 S)-(+)$-Camphorate Ligands: Counterion-Dependent Formation of a Hexanuclear Cage. Inorganic Chemistry, 2018, 58, pp.870-880. 10.1021/acs.inorgchem.8b02992 . cea-01957489

HAL Id: cea-01957489

https://hal-cea.archives-ouvertes.fr/cea-01957489

Submitted on 17 Dec 2018

HAL is a multi-disciplinary open access archive for the deposit and dissemination of scientific research documents, whether they are published or not. The documents may come from teaching and research institutions in France or abroad, or from public or private research centers.
L'archive ouverte pluridisciplinaire HAL, est destinée au dépôt et à la diffusion de documents scientifiques de niveau recherche, publiés ou non, émanant des établissements d'enseignement et de recherche français ou étrangers, des laboratoires publics ou privés. 


\title{
Chiral Discrete and Polymeric Uranyl Ion Complexes with $(1 R, 3 S)-(+)$-Camphorate Ligands: Counterion-Dependent Formation of a Hexanuclear Cage
}

\author{
Pierre Thuéry, ${ }^{* \dagger} \dagger$ Youssef Atoini ${ }^{\ddagger}$ and Jack Harrowfield $* *$ \\ ${ }^{\dagger}$ NIMBE, CEA, CNRS, Université Paris-Saclay, CEA Saclay, 91191 Gif-sur-Yvette, France \\ ${ }^{\ddagger}$ ISIS, Université de Strasbourg, 8 allée Gaspard Monge, 67083 Strasbourg, France
}

\begin{abstract}
Reaction of $(1 R, 3 S)-(+)$-camphoric acid $\left(\mathrm{H}_{2} \mathrm{cam}\right)$ with uranyl ions under solvo-hydrothermal conditions and in the presence of bulky countercations gave five chiral complexes of varying dimensionality. $\left[\mathrm{Cu}\left(R, S-\mathrm{Me}_{6} \mathrm{cyclam}\right)\right]\left[\mathrm{UO}_{2}(\mathrm{Hcam})_{2}(\mathrm{HCOO})_{2}\right](\mathbf{1})$ and $\left[\mathrm{Ni}\left(R, S-\mathrm{Me}_{6} \mathrm{cyclam}\right)\right]\left[\mathrm{UO}_{2}(\mathrm{cam})(\mathrm{HCOO})_{2}\right](\mathbf{2})$, in which the formate coligand is formed in situ, involve very similar countercations, but $\mathbf{1}$ is a discrete, mononuclear complex, whereas 2 crystallizes as a one-dimensional (1D) coordination polymer, and NH-bond donation by the macrocyclic ligand of the countercation complexes is present in both. $\left[\mathrm{Co}(\mathrm{en})_{3}\right]\left[\left(\mathrm{UO}_{2}\right)_{4}(\mathrm{cam})(R, R \text {-tart })_{2}(\mathrm{OH})\right] \cdot 3 \mathrm{H}_{2} \mathrm{O}(3)$, in which en is ethylenediamine and $\mathrm{H}_{4} R, R$-tart is $R, R$-tartaric acid, contains three enantiomerically pure chiral species, and it displays a two-dimensional (2D) arrangement, with the countercation again involved in NH-bond donation. While $\left[\mathrm{PPh}_{4}\right]\left[\mathrm{UO}_{2}(\mathrm{cam})\left(\mathrm{NO}_{3}\right)\right](4)$ is a $1 \mathrm{D}$ polymer, $\left[\mathrm{PPh}_{3} \mathrm{Me}_{3}\left[\mathrm{NH}_{4}\right]_{3}\left[\left(\mathrm{UO}_{2}\right)_{6}(\mathrm{cam})_{9}\right](\mathbf{5})\right.$, is a discrete, homochiral and homoleptic hexanuclear cage with $C_{3}$ point symmetry and a trigonal prismatic arrangement of the uranium atoms. This cage differs from the octanuclear, pseudo-cubic uranyl camphorate species previously described, thus providing an example of modulation of the cage size through variation of the structure-directing counterions. The cage in $\mathbf{5}$ is closely associated to three $\mathrm{PPh}_{3} \mathrm{Me}^{+}$cations, two of them outside and with their methyl group directed toward the prism basis centre, and one inside the cage cavity. While complex $\mathbf{5}$ is nonluminescent, complexes $\mathbf{1}$ and $\mathbf{4}$ have emission spectra in the solid state typical of equatorially hexacoordinated uranyl complexes. Solid-state photoluminescence quantum yields of 2 and $23 \%$ have been measured for complexes 1 and 4, respectively.
\end{abstract}




\section{INTRODUCTION}

The generation of polymeric, oligomeric or oligonuclear cage rather than simple chelate structures by complexation of metal ions with multidentate ligands is to some extent dependent upon the nature of the particular metal ion and associated anions but, more importantly, is open to control through an appropriate choice of the ligand. ${ }^{1,2}$ Dicarboxylates, as a major subset of polycarboxylates, provide an example of a class of ligands which has been widely applied in the synthesis of both coordination polymers and oligonuclear cages,${ }^{3-13}$ the latter species being of particular interest because of the possibility that they may define cavities utilisable as selective reaction vessels. ${ }^{4,7}$ Two carboxylate substituents may be found posed on scaffolds of an enormous variety ranging from flexible polymethylene chains compatible with many different separations between the carboxylate groups to highly rigid cyclic structures imposing a relatively precise limit of separation. Even with the most rigid of scaffolds, however, some flexibility remains in that there is facile rotation about the $\mathrm{C}-\mathrm{CO}_{2}{ }^{-}$bond which can allow some variation in the $\mathrm{O} \cdots \mathrm{O}$ separations between the two carboxylate centres.

The versatility of the carboxylate unit as a donor species, where one or both of the oxygen atoms may be bound in both direct or bridging modes, is another important factor to be taken into consideration. Thus, on a rigid scaffold such as 1,3-disubstituted adamantane, for example, the complexation of uranyl $\operatorname{ion}^{14,15}$ (our particular interest) does not involve the formation of 8-membered chelate rings involving one oxygen of each carboxylate but does involve bridging through formation of 4-membered chelate rings $\left(\kappa^{2} O, O^{\prime}\right.$ mode $)$ from one or both carboxylate units as well as through binding of another uranyl ion to such a chelate and through separate interactions of each oxygen of a given carboxylate with two different uranyl ions $\left(\mu_{2}-\kappa^{1} O: \kappa^{1} O^{\prime}\right)$. All these are associated with the formation of polymeric arrays of various dimensionality depending on other constituents of the lattice. On a less rigid scaffold with adjacent carboxylate substituents as is found with cis-1,2-cyclohexanedicarboxylate, formation 
of 7-membered chelate rings does occur in some instances despite the apparently divergent axial-equatorial geometry of the carboxylate units, although such rings are only part of more extended bridged arrays. ${ }^{16,17}$

It is thus a little surprising that on the chiral scaffold of $(1 R, 3 S)-(+)$-camphoric acid $\left(\mathrm{H}_{2} \mathrm{cam}\right),{ }^{18}$ which is certainly sufficiently flexible to allow the carboxylate substituents to adopt the diaxial conformation bringing them into close proximity, as seen in the structure of the anhydride, ${ }^{19}$ there is seemingly no tendency to form 8 -membered chelate rings in its metal complexes. More significantly, while in its general coordination chemistry with separate metal cations camphorate is characterized by bridging roles where each carboxylate interacts with different metal ion units or a metal ion and a proton, as shown by a survey of the crystal structures reported in the Cambridge Structural Database (CSD, Version 5.39), ${ }^{20}$ and in particular by some uranyl ion complexes, ${ }^{21}$ introduction of a second cation, metallic or nonmetallic (including the proton), along with uranyl ion has been found to be an effective method for formation of a pseudo-cubic octanuclear cage species. ${ }^{22,23}$ To understand better the origin of this effect, we have therefore extended our studies of the influence of large cations on the structure of heterocationic uranyl complexes ${ }^{16,17,24-26}$ to the camphorate system.

We have recently shown that the structure-directing effects exerted by $\mathrm{PPh}_{4}{ }^{+}$and $\mathrm{PPh}_{3} \mathrm{Me}^{+}$cations promoted the formation of a discrete uranyl octanuclear cage with cis-1,2cyclohexanedicarboxylate, ${ }^{17}$ and of a discrete tetranuclear metallatricycle with 1,3adamantanediacetate ${ }^{26}$ so that their impact in the case of a ligand already known for its propensity to give cage complexes, such as $(1 R, 3 S)-(+)$-camphorate, was worth investigating. Cages and metallacycles are still relatively rare in uranyl chemistry, apart from the family of uranyl peroxides, ${ }^{27}$ and, in addition to those already mentioned, only about a dozen are known, ${ }^{28-39}$ most of them containing carboxylate ligands. Reported herein are five uranyl ion complexes synthesized from $(1 R, 3 S)-(+)$-camphoric acid, three of which include bulky $3 \mathrm{~d}-$ 
block metal-containing countercations, and the other two $\mathrm{PPh}_{4}{ }^{+}$and $\mathrm{PPh}_{3} \mathrm{Me}^{+}$cations. These complexes, which have been characterized by their crystal structure and, for some of them, their emission spectrum in the solid state, crystallize as one- or two-dimensional (1D or 2D) coordination polymers, or as discrete species, one of them a hexanuclear cage. A potentially important property of all these complexes is that due to their incorporation of enantiomerically pure $(1 R, 3 S)-(+)$-camphorate ligands, their crystals belong to chiral lattices. ${ }^{18}$

\section{EXPERIMENTAL SECTION}

Syntheses. Caution! Uranium is a radioactive and chemically toxic element, and uranium-containing samples must be handled with suitable care and protection.

$\mathrm{UO}_{2}\left(\mathrm{NO}_{3}\right)_{2} \cdot 6 \mathrm{H}_{2} \mathrm{O}$ (depleted uranium, R. P. Normapur, 99\%) was purchased from Prolabo, and $(1 R, 3 S)-(+)$-camphoric acid was from Aldrich. $R, S$-Me $\mathrm{M}_{6}$ cyclam (meso isomer of $7(R), 14(S)-5,5,7,12,12,14$-hexamethyl-1,4,8,11-tetraazacyclotetradecane) was prepared as described in the literature. ${ }^{40} \mathrm{~N}(R, S, R, S)-\left[\mathrm{M}\left(R, S-\mathrm{Me}_{6}\right.\right.$ cyclam $\left.)\left(\mathrm{NO}_{3}\right)_{2}\right](\mathrm{M}=\mathrm{Cu}, \mathrm{Ni})$ were synthesized as previously described..$^{25,41}$ Resolution of $\left[\operatorname{Co}(\mathrm{en})_{3}\right]^{3+}(\mathrm{en}=$ ethylenediamine $)$ by $R, R$-tartrate has been known for long, ${ }^{42,43}$ and $\Lambda$ - $\left[\mathrm{Co}(\mathrm{en})_{3}\right]\left(\mathrm{H}_{2} R, R\right.$-tart $) \mathrm{Cl} \cdot 2 \mathrm{H}_{2} \mathrm{O}$, where $\mathrm{H}_{4} R, R$ tart is $R, R$-tartaric acid, was obtained as described. Elemental analyses were performed by MEDAC Ltd. at Chobham, UK. For all syntheses of uranyl ion complexes, the mixtures in demineralized water/organic solvent were placed in $10 \mathrm{~mL}$ tightly closed glass vessels and heated at $140{ }^{\circ} \mathrm{C}$ under autogenous pressure.

$\left[\mathrm{Cu}\left(\mathrm{R}, \mathrm{S}-\mathrm{Me}_{6} \mathrm{Cyclam}\right)\right]\left[\mathrm{UO}_{2}(\mathrm{Hcam})_{2}(\mathrm{HCOO})_{2}\right]$ (1). (1R,3S)-(+)-Camphoric acid (20 mg, $0.10 \mathrm{mmol}), \quad \mathrm{UO}_{2}\left(\mathrm{NO}_{3}\right)_{2} \cdot 6 \mathrm{H}_{2} \mathrm{O} \quad(35 \mathrm{mg}, \quad 0.07 \mathrm{mmol})$, and $\mathrm{N}(R, S, R, S)-[\mathrm{Cu}(R, S-$ $\mathrm{Me}_{6}$ cyclam $\left.)\left(\mathrm{NO}_{3}\right)_{2}\right](24 \mathrm{mg}, 0.05 \mathrm{mmol})$ were dissolved in water $(0.7 \mathrm{~mL})$ and DMF $(0.2 \mathrm{~mL})$. Purple crystals of complex 1 were obtained within two weeks (36 mg, 65\% yield based on the 
acid). Anal. Calcd for $\mathrm{C}_{38} \mathrm{H}_{68} \mathrm{CuN}_{4} \mathrm{O}_{14} \mathrm{U}: \mathrm{C}, 41.25 ; \mathrm{H}, 6.19 ; \mathrm{N}, 5.06$. Found: $\mathrm{C}, 41.31 ; \mathrm{H}, 6.05$; $\mathrm{N}, 5.59 \%$.

$\left[\mathrm{Ni}\left(\mathrm{R}, \mathrm{S}-\mathrm{Me}_{6} \mathrm{Cyclam}\right)\right]\left[\mathrm{UO}_{2}(\mathrm{cam})(\mathrm{HCOO})_{2}\right]$ (2). (1R,3S)-(+)-Camphoric acid (20 mg, 0.10 $\mathrm{mmol}), \mathrm{UO}_{2}\left(\mathrm{NO}_{3}\right)_{2} \cdot 6 \mathrm{H}_{2} \mathrm{O}(35 \mathrm{mg}, 0.07 \mathrm{mmol})$, and $\mathrm{N}(R, S, R, S)-\left[\mathrm{Ni}\left(R, S-\mathrm{Me}_{6} \mathrm{cyclam}\right)\left(\mathrm{NO}_{3}\right)_{2}\right]$ (23 mg, $0.05 \mathrm{mmol})$ were dissolved in water $(0.5 \mathrm{~mL})$ and DMF $(0.2 \mathrm{~mL})$. Orange crystals of complex 2 were obtained in low yield within two weeks.

$\left[\mathrm{CO}(e n)_{3}\right]\left[\left(\mathrm{UO}_{2}\right)_{4}(\mathrm{cam})(\mathrm{R}, \mathrm{R} \text {-tart })_{2}(\mathrm{OH})\right] \cdot 3 \mathrm{H}_{2} \mathrm{O}$ (3). (1R,3S)-(+)-Camphoric acid (20 mg, $0.10 \mathrm{mmol}), \mathrm{UO}_{2}\left(\mathrm{NO}_{3}\right)_{2} \cdot 6 \mathrm{H}_{2} \mathrm{O}(35 \mathrm{mg}, 0.07 \mathrm{mmol})$, and $\Lambda$-[Co(en $\left.)_{3}\right]\left(\mathrm{H}_{2} R, R\right.$-tart $) \mathrm{Cl} \cdot 2 \mathrm{H}_{2} \mathrm{O}(23$ $\mathrm{mg}, 0.05 \mathrm{mmol})$ were dissolved in water $(0.6 \mathrm{~mL})$ and acetonitrile $(0.2 \mathrm{~mL})$. Orange crystals of complex $\mathbf{3}$ were obtained in low yield within three days.

$\left[\mathrm{PPh}_{4}\right]\left[\mathrm{UO}_{2}(\mathrm{cam})\left(\mathrm{NO}_{3}\right)\right] \quad$ (4). $(1 \mathrm{R}, 3 \mathrm{~S})-(+)$-Camphoric acid $(20 \mathrm{mg}, 0.10 \mathrm{mmol})$, $\mathrm{UO}_{2}\left(\mathrm{NO}_{3}\right)_{2} \cdot 6 \mathrm{H}_{2} \mathrm{O}(35 \mathrm{mg}, 0.07 \mathrm{mmol})$, and $\mathrm{PPh}_{4} \mathrm{Br}(42 \mathrm{mg}, 0.10 \mathrm{mmol})$ were dissolved in water $(0.5 \mathrm{~mL})$ and acetonitrile $(0.2 \mathrm{~mL})$. Yellow crystals of complex 4 were obtained within four days (50 mg, $82 \%$ yield based on $\mathrm{U}$ ). Anal. Calcd for $\mathrm{C}_{34} \mathrm{H}_{34} \mathrm{NO}_{9} \mathrm{PU}$ : C, 46.96; H, 3.94; N, 1.61 . Found: C, 46.30; H, 3.76; N, 1.64\%.

$\left[\mathrm{PPh}_{3} \mathrm{Me}\right]_{3}\left[\mathrm{NH}_{4}\right]_{3}\left[\left(\mathrm{UO}_{2}\right)_{6}(\mathrm{cam})_{9}\right](5) .(1 R, 3 S)-(+)$-Camphoric acid (20 mg, $\left.0.10 \mathrm{mmol}\right)$, $\mathrm{UO}_{2}\left(\mathrm{NO}_{3}\right)_{2} \cdot 6 \mathrm{H}_{2} \mathrm{O}(35 \mathrm{mg}, 0.07 \mathrm{mmol})$, and $\mathrm{PPh}_{3} \mathrm{MeBr}(36 \mathrm{mg}, 0.10 \mathrm{mmol})$ were dissolved in water $(0.9 \mathrm{~mL})$, acetonitrile $(0.2 \mathrm{~mL})$ and DMF $(0.2 \mathrm{~mL})$. Yellow crystals of complex 5 were obtained within three weeks ( $22 \mathrm{mg}, 46 \%$ yield based on the acid). Anal. Calcd for $\mathrm{C}_{147} \mathrm{H}_{192} \mathrm{~N}_{3} \mathrm{O}_{48} \mathrm{P}_{3} \mathrm{U}_{6}: \mathrm{C}, 41.16 ; \mathrm{H}, 4.51 ; \mathrm{N}, 0.98$. Found: C, 40.66; H, 4.63; N, 1.80\%. The discrepancy between calculated and found values may be due to the presence of lattice solvent molecules (water, acetonitrile or DMF) which could not be resolved in the crystal structure (see below). 
Crystallography. The data were collected at 100(2) K on a Nonius Kappa-CCD area detector diffractometer ${ }^{44}$ using graphite-monochromated Mo K $\alpha$ radiation $(\lambda=0.71073 \AA)$. The crystals were introduced into glass capillaries with a protective coating of Paratone- $\mathrm{N}$ oil (Hampton Research). The unit cell parameters were determined from ten frames, then refined on all data. The data (combinations of $\varphi$ - and $\omega$-scans with a minimum redundancy of 4 for $90 \%$ of the reflections) were processed with HKL2000. ${ }^{45}$ Absorption effects were corrected empirically with the program SCALEPACK. ${ }^{45}$ The structures were solved by intrinsic phasing with SHELXT, ${ }^{46}$ expanded by subsequent difference Fourier synthesis and refined by fullmatrix least-squares on $F^{2}$ with SHELXL-2014. ${ }^{47}$ All non-hydrogen atoms were refined with anisotropic displacement parameters. The hydrogen atoms bound to oxygen and nitrogen atoms were retrieved from difference Fourier maps when possible (see details below), and the carbonbound hydrogen atoms were introduced at calculated positions. All hydrogen atoms were treated as riding atoms with an isotropic displacement parameter equal to 1.2 times that of the parent atom (1.5 for $\mathrm{CH}_{3}$, with optimized geometry). Large voids in the lattices of compounds $\mathbf{3}$ and $\mathbf{5}$ indicate the presence of unresolved solvent molecules, whose contribution to the structure factors was taken into account with PLATON/SQUEEZE. ${ }^{48}$ Crystal data and structure refinement parameters are given in Table 1 . The molecular plots were drawn with ORTEP-3, ${ }^{49}$ and the polyhedral representations with VESTA. ${ }^{50}$ The topological analyses were conducted with TOPOS. ${ }^{51}$ Special details, when present, are as follows.

Complex 3. Restraints on bond lengths, angles and displacement parameters were applied for the atoms of the badly resolved camphorate molecule. The hydrogen atom bound to O25 was found on a difference Fourier map, but not those of the lattice water molecules, one of which was given an occupancy factor of 0.5 in order to retain an acceptable displacement parameter. 
Complex 5 . The crystals, and consequently the diffraction data were of very poor quality and the refinement required the use of extensive restraints on bond lengths, angles and displacement parameters. The hydrogen atoms of the $\mathrm{NH}_{4}{ }^{+}$cations, which are disordered and were given occupancy parameters of $1 / 3$ for charge balance and to retain acceptable displacement parameters, were neither found, nor introduced.

Table 1. Crystal Data and Structure Refinement Details

\begin{tabular}{|c|c|c|c|c|c|}
\hline & 1 & 2 & 3 & 4 & 5 \\
\hline chemical formula & $\mathrm{C}_{38} \mathrm{H}_{68} \mathrm{CuN}_{4} \mathrm{O}_{14} \mathrm{U}$ & $\mathrm{C}_{28} \mathrm{H}_{52} \mathrm{~N}_{4} \mathrm{NiO}_{10} \mathrm{U}$ & $\mathrm{C}_{24} \mathrm{H}_{49} \mathrm{CoN}_{6} \mathrm{O}_{28} \mathrm{U}_{4}$ & $\mathrm{C}_{34} \mathrm{H}_{34} \mathrm{NO}_{9} \mathrm{PU}$ & $\mathrm{C}_{147} \mathrm{H}_{192} \mathrm{~N}_{3} \mathrm{O}_{48} \mathrm{P}_{3} \mathrm{U}_{6}$ \\
\hline$M\left(\mathrm{~g} \mathrm{~mol}^{-1}\right)$ & 1106.53 & 901.47 & 1880.74 & 869.62 & 4290.12 \\
\hline cryst syst & triclinic & orthorhombic & orthorhombic & monoclinic & hexagonal \\
\hline space group & $P 1$ & $P 2{ }_{1}{ }_{1} 2_{1}$ & $P 2{ }_{1}{ }_{1} 2$ & $P 2_{1}$ & $\mathrm{PG}_{3}$ \\
\hline$a(\AA)$ & $8.2223(4)$ & $9.1167(3)$ & $17.3555(8)$ & $8.0460(3)$ & $15.9876(7)$ \\
\hline$b(\AA)$ & $11.4446(3)$ & $18.4978(7)$ & $21.4656(13)$ & $16.2439(10)$ & $15.9876(7)$ \\
\hline$c(\AA)$ & $13.2749(6)$ & $19.5856(5)$ & $13.8492(6)$ & $12.9430(8)$ & $39.925(3)$ \\
\hline$\alpha(\mathrm{deg})$ & $68.345(3)$ & 90 & 90 & 90 & 90 \\
\hline$\beta(\mathrm{deg})$ & $86.979(2)$ & 90 & 90 & $100.564(4)$ & 90 \\
\hline$\gamma(\mathrm{deg})$ & $76.794(3)$ & 90 & 90 & 90 & 120 \\
\hline$V\left(\AA^{3}\right)$ & $1129.62(8)$ & $3302.90(19)$ & $5159.5(5)$ & $1662.96(16)$ & $8837.8(12)$ \\
\hline$Z$ & 1 & 4 & 4 & 2 & 2 \\
\hline reflns collcd & 61854 & 110279 & 88767 & 55097 & 143094 \\
\hline indep reflns & 8491 & 6244 & 9766 & 6280 & 9817 \\
\hline obsd reflns $[I>2 \sigma(I)]$ & 8482 & 6005 & 8176 & 5924 & 4703 \\
\hline$R_{\text {int }}$ & 0.025 & 0.022 & 0.038 & 0.020 & 0.101 \\
\hline params refined & 536 & 407 & 577 & 419 & 611 \\
\hline$R_{1}$ & 0.029 & 0.026 & 0.047 & 0.034 & 0.063 \\
\hline$w R_{2}$ & 0.074 & 0.066 & 0.117 & 0.088 & 0.208 \\
\hline$S$ & 1.055 & 1.070 & 1.038 & 1.030 & 1.022 \\
\hline$\Delta \rho_{\min }\left(\mathrm{e} \AA^{-3}\right)$ & -0.72 & -1.26 & -1.38 & -1.74 & -2.11 \\
\hline$\Delta \rho_{\max }\left(\mathrm{e} \AA^{-3}\right)$ & 0.57 & 0.70 & 1.19 & 0.76 & 1.21 \\
\hline Flack parameter & $0.014(7)$ & $0.015(9)$ & $0.053(17)$ & $0.010(11)$ & $0.09(2)$ \\
\hline
\end{tabular}

Luminescence Measurements. Emission spectra were recorded on solid samples using a Horiba-Jobin-Yvon IBH FL-322 Fluorolog 3 spectrometer equipped with a $450 \mathrm{~W}$ xenon arc lamp, double-grating excitation and emission monochromator $(2.1 \mathrm{~nm} / \mathrm{mm}$ of dispersion; 1200 grooves/mm) and a TBX-04 single photon-counting detector. The powdered compounds were put into a quartz tube and pressed to the wall of the tube, and the measurements were performed using the right-angle mode. An excitation wavelength of $420 \mathrm{~nm}$, a commonly used point although only part of a broad manifold, was used in all cases and the emission was monitored between 450 and $650 \mathrm{~nm}$. The quantum yield measurements were performed by using a 
Hamamatsu Quantaurus C11347 absolute photoluminescence quantum yield spectrometer and exciting the samples between 300 and $400 \mathrm{~nm}$.

\section{RESULTS AND DISCUSSION}

Synthesis. Crystals of complexes 1-5 were grown under solvo-hydrothermal conditions, at a temperature of $140{ }^{\circ} \mathrm{C}$, with the organic cosolvent being $\mathrm{N}, \mathrm{N}$ dimethylformamide (1 and 2), acetonitrile (3 and 4), or a mixture thereof (5). The crystals were deposited directly from the pressurized and heated reaction mixtures and not as a result of subsequent cooling. The uranium/dicarboxylate ligand ratio was 7:10 in all cases, so as to favour the formation of an anionic species, but the expected ratio of 2:3 is retained in complex $\mathbf{5}$ only, while a 1:2 ratio is found in $\mathbf{1}, 1: 1$ in $\mathbf{2}$ and $\mathbf{4}$, and 4:1 in 3. Coligands (formate, tartrate, nitrate) are present in all the last cases, while $\mathbf{5}$ is homoleptic. The composition of the crystalline materials isolated in the present work provides further illustration of the vagaries of solvothermal synthesis. Thus, in four of the five complexes the camphorate dianion $\mathrm{cam}^{2-}$ is present but in complex 1 the $\mathrm{Hcam}^{-}$monoanion is found, giving rise to a different stoichiometry to that of complex $\mathbf{2}$, despite the identical isomeric form and very closely similar size of the cations $\left[\mathrm{Cu}\left(R, S-\mathrm{Me}_{6} \text { cyclam }\right)\right]^{2+}$ and $\left[\mathrm{Ni}\left(R, S-\mathrm{Me}_{6} \text { cyclam }\right)\right]^{2+}$ as well as the use of identical reaction conditions. The formate ligands present in both complexes arise from hydrolysis of DMF under the reaction conditions, ${ }^{24,52}$ a process that also gives rise to dimethylammonium cations that, in many other related systems but not here, are found as components of the crystalline products. Despite the use of DMF as a cosolvent in the synthesis of complex 5, neither formate nor dimethylammonium is present but ammonium ion, presumably derived from the acetonitrile cosolvent, ${ }^{17,26,38}$ is. It is not, however present in either complex $\mathbf{3}$ or complex $\mathbf{4}$, both of which were deposited from aqueous acetonitrile solvent. It is also notable that although nitrate was present in all the reaction mixtures, it appears in complex 4 only. Complex $\mathbf{3}$ is the only one to contain an hydroxo ligand, possibly in reflection of the weak 
basicity induced by the presence of tartrate anion. Thus, while our efforts to associate different large cations with anionic uranyl camphorate species were successful in every case, it cannot be said that the nature of the different cations must have been the sole influence upon the composition of the isolated crystals. The syntheses therefore demand structural studies to define in detail the interactions that determine the form of the crystal lattices.

Crystal Structures. Complex 1, $\left[\mathrm{Cu}\left(R, S-\mathrm{Me}_{6}\right.\right.$ cyclam $\left.)\right]\left[\mathrm{UO}_{2}(\mathrm{Hcam})_{2}(\mathrm{HCOO})_{2}\right]$, can be described as the simplest of the present series in that its crystal lattice contains a discrete, mononuclear uranyl complex. The asymmetric unit contains one uranyl cation chelated in $\kappa^{2} O, O^{\prime}$ mode by two mono-deprotonated camphorate ligands, and bound to two monodentate formate anions in trans arrangement (Figure 1). As in all other compounds in this series, the $\mathrm{U}-\mathrm{O}$ bond lengths assume usual values $[\mathrm{U}-\mathrm{O}(\mathrm{oxo}) 1.770(8)$ and $1.779(9) \AA$, $\mathrm{U}-\mathrm{O}$ (camphorate)

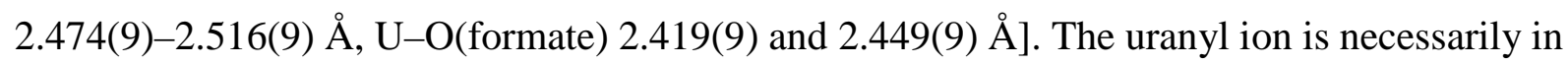
a chiral environment but its $\mathrm{O}_{6}$ equatorial array is very close to planar and any asymmetry is most obvious only in the orientations of the two formate ligands. The $\mathrm{N}(R, S, R, S)-[\mathrm{Cu}(R, S-$ $\mathrm{Me}_{6}$ cyclam) $]^{2+}$ cation is formally achiral, and the copper(II) cation is bound to the four nitrogen atoms of the macrocyclic ligand $[\mathrm{Cu}-\mathrm{N} 2.019(11)-2.045(10) \AA]$, and forms also a longer contact, at 2.642(9) $\AA$ with the formate atom O12, this possible five-coordinate nature distinguishing the role of the macrocycle complex from that it has in the lattice of the uranyl pimelate-oxalate complex $\left[\mathrm{Cu}\left(R, S-\mathrm{Me}_{6}\right.\right.$ cyclam $\left.)\right]\left[\left(\mathrm{UO}_{2}\right)_{2}(\mathrm{C} 7)_{2}\left(\mathrm{C}_{2} \mathrm{O}_{4}\right)\right] \cdot 4 \mathrm{H}_{2} \mathrm{O},{ }^{41}$ where the metal ion remains four-coordinate and the complex acts solely as an hydrogen bond donor. The mononuclear uranyl units are linked into chains parallel to the $c$ axis through hydrogen bonding involving the camphorate carboxylic protons and the uncoordinated oxygen atoms of the

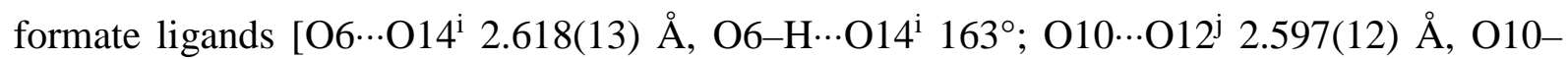
$\mathrm{H} \cdots \mathrm{O} 12^{\mathrm{j}} 174^{\circ}$; symmetry codes: $\left.\mathrm{i}=x, y, z+1 ; \mathrm{j}=x, y, z-1\right]$. These chains are in turn linked 


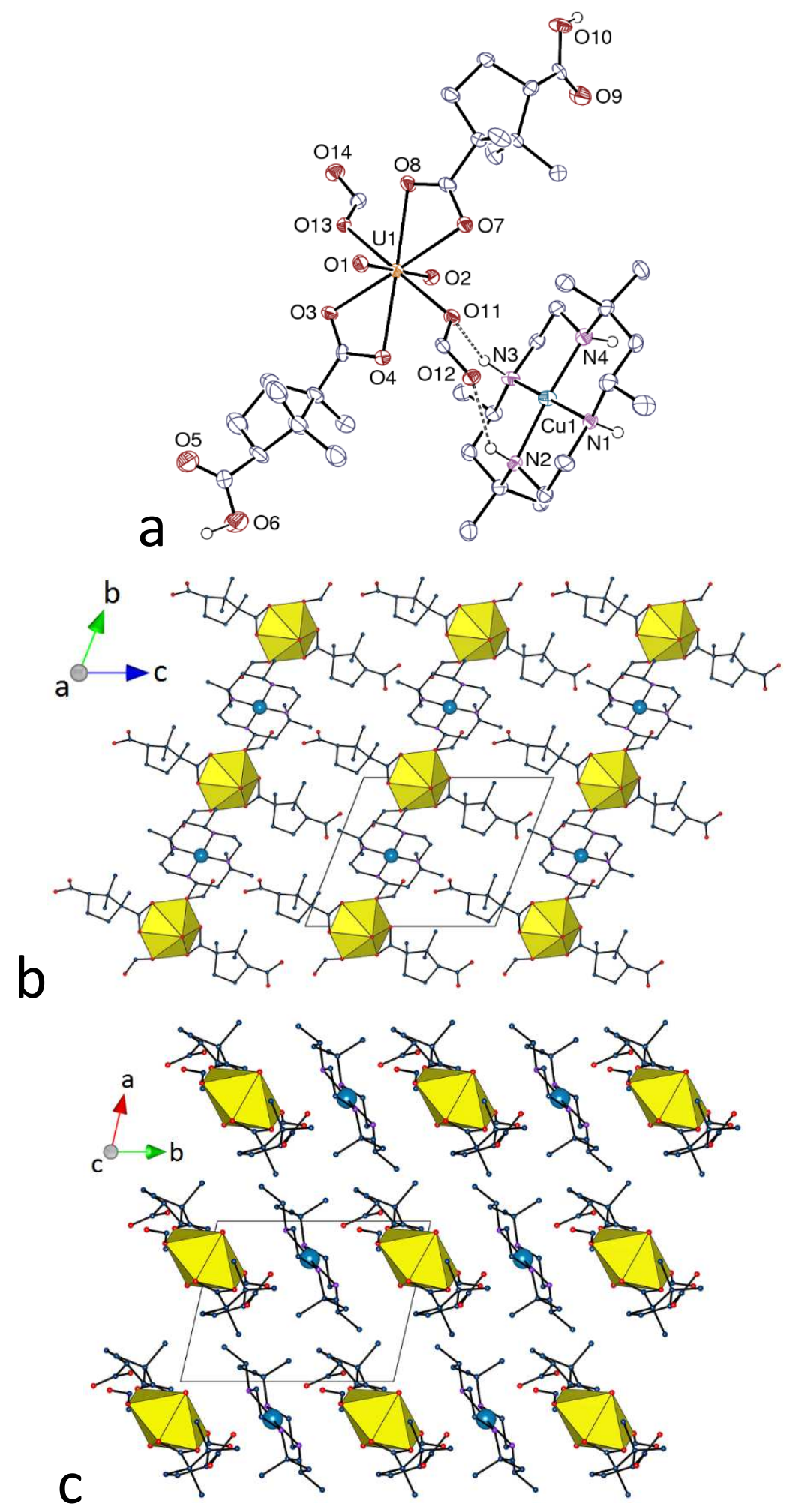

Figure 1. (a) View of compound 1. Displacement ellipsoids are drawn at the $50 \%$ probability level. Carbon-bound hydrogen atoms are omitted and hydrogen bonds are shown as dashed lines. (b) and (c) Two views of the packing with uranium coordination polyhedra colored yellow and copper(II) ions shown as blue spheres, and hydrogen atoms omitted. 
through possible copper(II) axial coordination and $\mathrm{NH} \cdots \mathrm{O}$ hydrogen bonds involving camphorate and formate as acceptors $\left[\mathrm{N} \cdots \mathrm{O}\right.$ 2.961(14)-3.059(12) $\AA$, N-H $\left.\cdots \mathrm{O} 122-152^{\circ}\right]$ to form two-dimensional (2D) sheets parallel to (100). These interactions are all visible on the Hirshfeld surfaces ${ }^{53}$ calculated with CrystalExplorer, ${ }^{54}$ as well as several $\mathrm{CH} \cdots \mathrm{O}$ hydrogenbonding interactions, ${ }^{55,56}$ some of them between sheets. The Kitaigorodski packing index (KPI) calculated with PLATON, ${ }^{57} 0.67$, is indicative of a compact packing with no significant solventaccessible space.

Despite the almost identical form of the two cations $\mathrm{N}(R, S, R, S)-\left[\mathrm{Cu}\left(R, S-\mathrm{Me}_{6} \text { cyclam }\right)\right]^{2+}$ and $\quad \mathrm{N}(R, S, R, S)-\left[\mathrm{Ni}\left(R, S-\mathrm{Me}_{6} \text { cyclam }\right)\right]^{2+}, \quad$ complex $\quad \mathbf{2}, \quad\left[\mathrm{Ni}\left(R, S-\mathrm{Me}_{6} \mathrm{cyclam}\right)\right]\left[\mathrm{UO}_{2}(\mathrm{cam})-\right.$ $(\mathrm{HCOO})_{2}$ ], differs from complex $\mathbf{1}$ in several respects. The environment of the unique uranyl cation is identical to that in $\mathbf{1}[\mathrm{U}-\mathrm{O}($ oxo $) 1.777(4)$ and $1.781(4) \AA$, U-O(camphorate) $2.480(6)-$ 2.522(5) $\AA$, U-O(formate) 2.406(4) and 2.408(4) $\AA$ ], but here the fully deprotonated camphorate dianion is bridging and generates a ribbon-shaped, one-dimensional (1D) coordination polymer parallel to the $c$ axis (Figure 2). The nickel(II) centre is bound to the four nitrogen atoms [Ni-N 1.938(6)-1.953(7) $\AA$ ], but it is not involved in axial coordination interactions and the macrocycle complex unit functions essentially as an hydrogen bond donor. Here, there is a parallel with the behaviour of the cations in the complex $[\mathrm{Ni}(R, S$ $\mathrm{Me}_{6}$ cyclam $\left.)\right]\left[\mathrm{Ni}\left(R, S-\mathrm{Me}_{6}\right.\right.$ cyclam $\left.)\left(\mathrm{H}_{2} \mathrm{O}\right)_{2}\right]\left[\left(\mathrm{UO}_{2}\right)_{2}(t-1,2-\mathrm{chdc})_{2}(\mathrm{O})\right]_{2} \quad(t-1,2-\mathrm{chdc}=$ trans-1,2cyclohexanedicarboxylate), ${ }^{25}$ although the structure of this material does show that expansion of the coordination sphere of $\mathrm{Ni}^{\mathrm{II}}$ by diaxial coordination is possible. The two formate ligands located in trans positions on the uranium cation again have important roles in the hydrogen bond network involving the counterions, acting as bridges through their two oxygen atoms between the pairs of $\mathrm{NH}$ groups projecting to each side of the $\mathrm{NiN}_{4}$ plane $[\mathrm{N} \cdots \mathrm{O} 2.788(9)-$ $3.125(9) \AA, \mathrm{N}-\mathrm{H} \cdots \mathrm{O} 139-176^{\circ}$ ]. In this way, each polymer strand is linked to four others, giving 
rise to the three-dimensional (3D) connectivity of the lattice. No solvent accessible space is present (KPI 0.70).
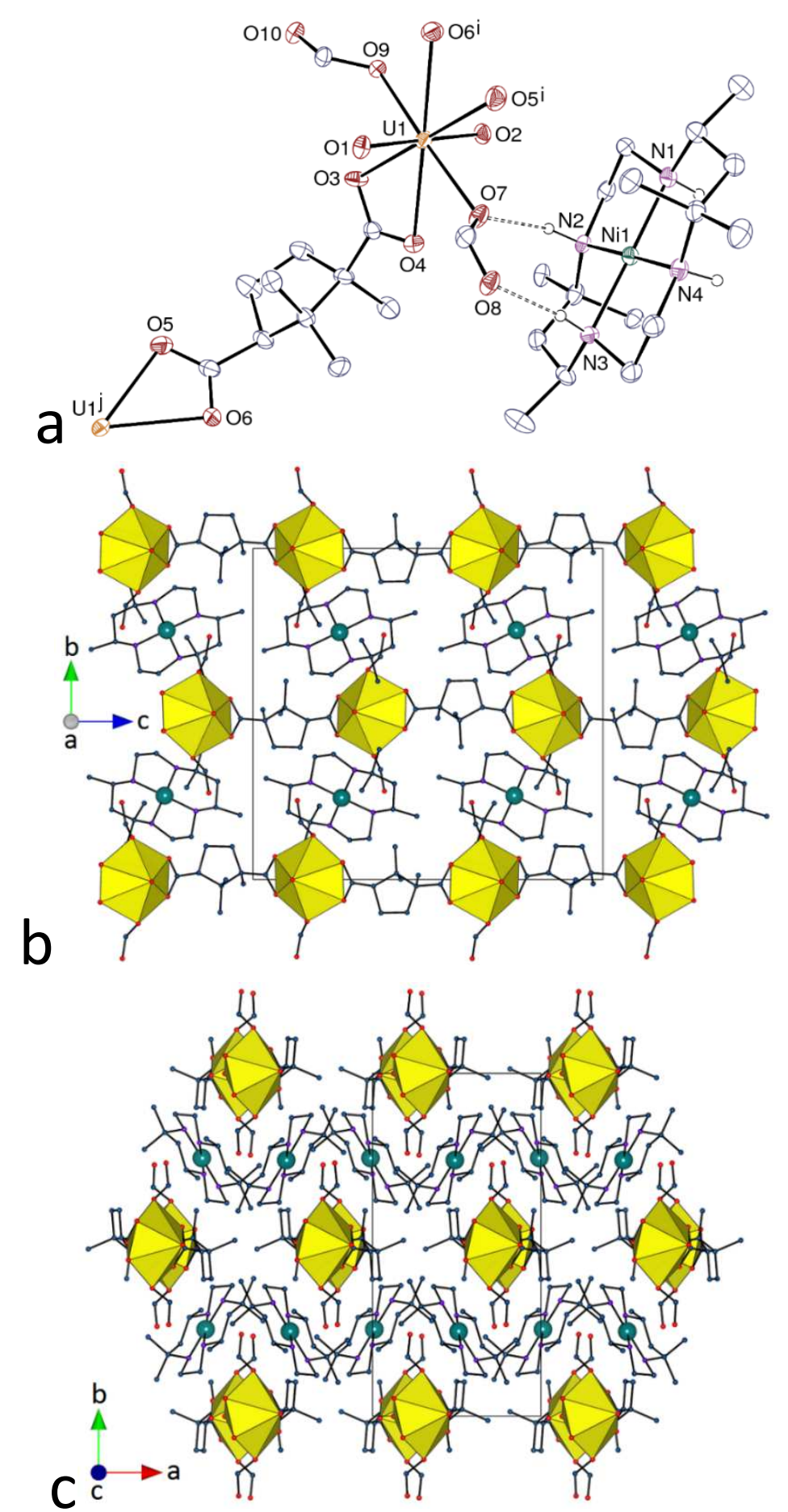

Figure 2. (a) View of compound 2. Displacement ellipsoids are drawn at the $30 \%$ probability level. Carbon-bound hydrogen atoms are omitted and hydrogen bonds are shown as dashed lines. Symmetry codes: $\mathrm{i}=3 / 2-x, 1-y, z$ $-1 / 2 ; \mathrm{j}=3 / 2-x, 1-y, z+1 / 2$. (b) and (c) Two views of the packing with uranium coordination polyhedra colored yellow and nickel(II) ions shown as blue spheres, and hydrogen atoms omitted. 
Complex 3, $\left[\mathrm{Co}(\mathrm{en})_{3}\right]\left[\left(\mathrm{UO}_{2}\right)_{4}(\mathrm{cam})(R, R \text {-tart })_{2}(\mathrm{OH})\right] \cdot 3 \mathrm{H}_{2} \mathrm{O}(\mathbf{3})$, where $R, R$-tart ${ }^{4-}$ is the tetra-anion of $R, R$-tartaric acid, is stereochemically the most complicated of the present species, containing three chiral components, $\Lambda$ - $\left[\mathrm{Co}(\mathrm{en})_{3}\right]^{3+}, R, R$ - $\operatorname{tart}^{4-}$ and $\mathrm{cam}^{2-}$, all of which are configurationally stable (to at least moderately elevated temperatures) but conformationally labile. The ability to prepare a reaction mixture from enantiomerically pure components, however, was expected to limit the number of possible product forms and the crystals obtained, albeit in low yield, appeared to be uniform. The asymmetric unit contains four independent uranium atoms, each of them being chelated by one carboxylate and one hydroxylic group from one $R, R$-tart ${ }^{4-}$ ligand (Figure 3), a coordination mode previously found in $\left[\mathrm{UO}_{2}\left(\mathrm{H}_{2} \operatorname{tart}\right)\left(\mathrm{H}_{2} \mathrm{O}\right)\right]$, the only other uranyl tartrate complex reported,${ }^{58}$ and also in complexes with citrate, malate and citramalate ligands. ${ }^{59}$ The coordination sphere is completed differently for each uranium atom. $\mathrm{U} 1$ and $\mathrm{U} 2$ are both chelated by two hydroxylic groups of one ligand, U1 being also chelated in a very asymmetric fashion by one camphorate ligand, being thus in a very distorted hexagonal bipyramidal environment, while U2 is bound to only one camphorate oxygen donor. U3 is chelated by the two carboxylic groups of a second tartrate ligand and bound to one camphorate donor, and U4 is bound to two tartrate and one camphorate ligands and to a hydroxide anion, both U3 and U4 being thus in pentagonal bipyramidal environments, like U2. Overall, the bond lengths around uranium are unexceptional [U-O(oxo) 1.742(15)-1.794(15) ̊, U-

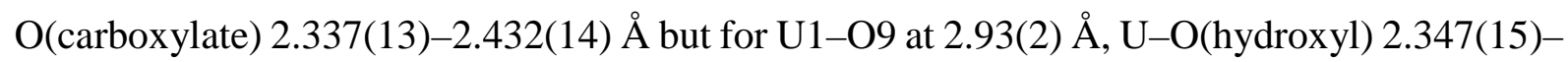
2.413(13) $\AA$ ]. Each tartrate ligand is bound to four metal centres, as is also the camphorate ligand, the latter through bis $\left(\mu_{2}-\kappa^{1} O: \kappa^{1} O^{\prime}\right)$ coordination of the diequatorial carboxylate groups (with additional more distant contact of U1 with O9); each pair of uranyl ions bridged by a camphorate carboxylate are also being bridged by a deprotonated tartrate hydroxyl. This 

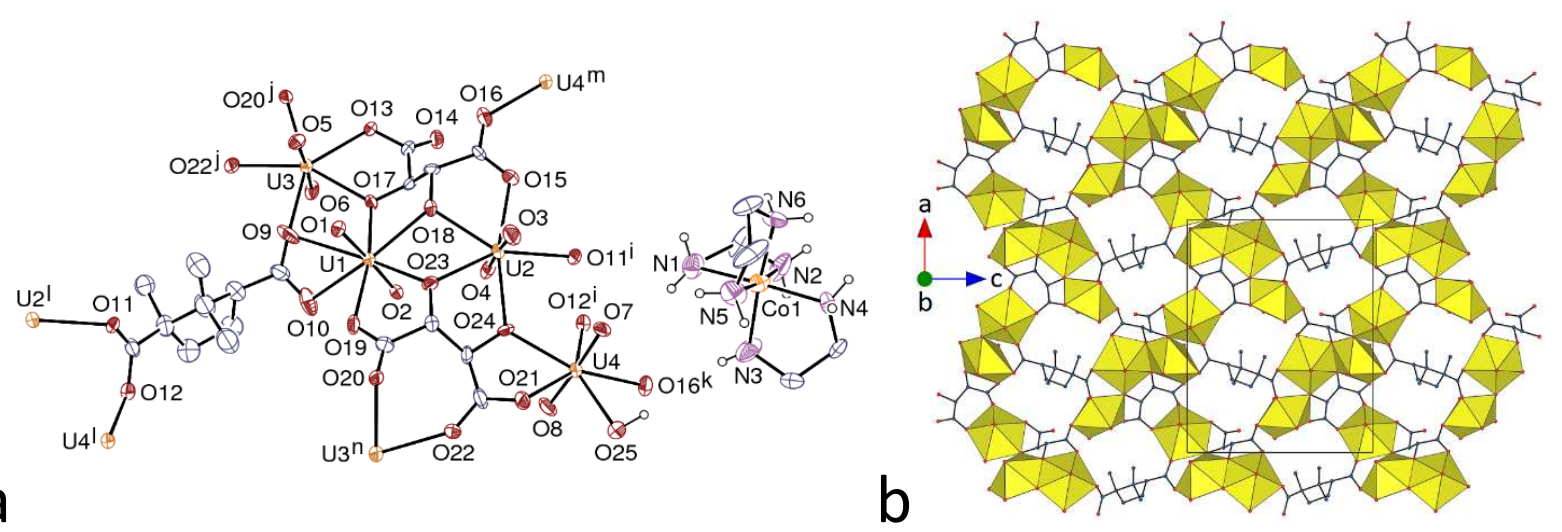

a
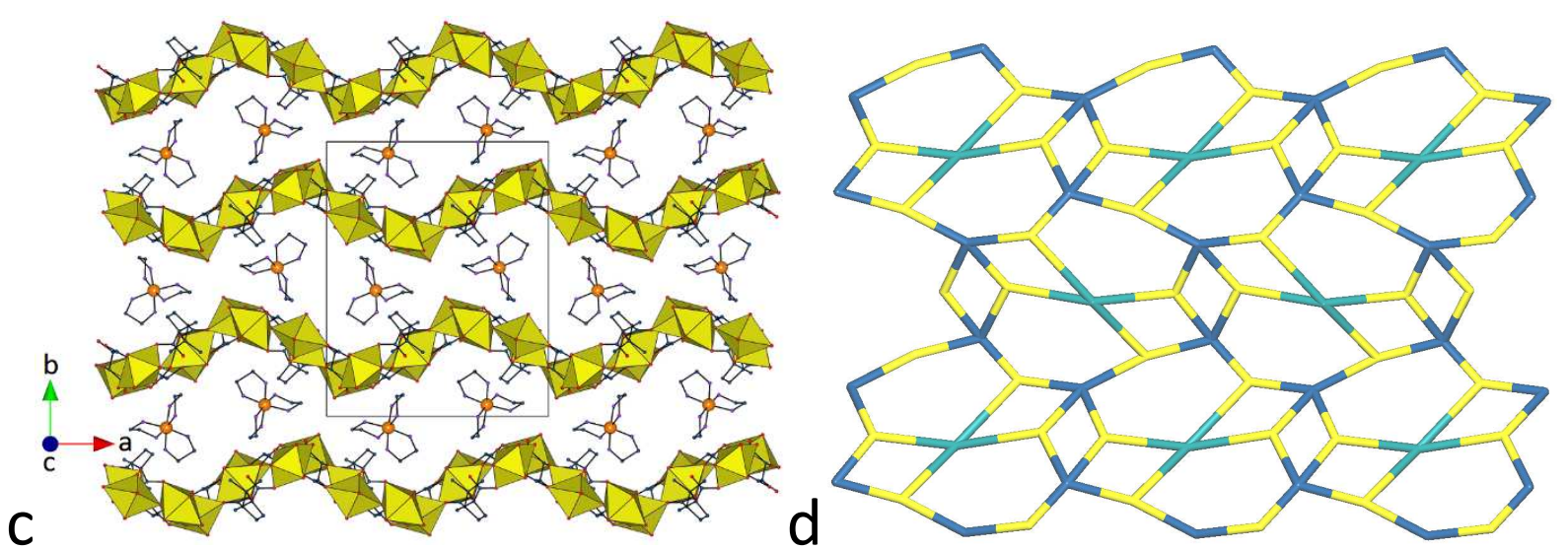

Figure 3. (a) View of compound 3. Displacement ellipsoids are drawn at the $30 \%$ probability level. Carbon-bound hydrogen atoms are omitted. Symmetry codes: $\mathrm{i}=x, y, z+1 ; \mathrm{j}=x+1 / 2,1 / 2-y,-z ; \mathrm{k}=x-1 / 2,1 / 2-y, 1-z ; 1=$ $x, y, z-1 ; \mathrm{m}=x+1 / 2,1 / 2-y, 1-z ; \mathrm{n}=x-1 / 2,1 / 2-y,-z$. (b) View of the $2 \mathrm{D}$ network. (c) View of the packing with layers edge-on and cobalt(III) ions shown as orange spheres. (d) Nodal representation of the 2D network (yellow, uranium; dark blue, tartrate ligands; light blue, camphorate ligands).

connectivity results in the formation of a tetra-nodal 2D assembly parallel to (010), which has the point (Schläfli) symbol $\left\{4.6^{2}\right\}_{2}\left\{4^{2} \cdot 6^{2} .8^{2}\right\}\left\{4^{2} \cdot 6^{3} .8\right\}_{2}\left\{4^{2} \cdot 6\right\}_{2}$ and is represented in Figure $3 \mathrm{~d}$. The slightly undulating layers are separated by the $\left[\mathrm{Co}(\mathrm{en})_{3}\right]^{3+}$ counterions. Structural studies of $\left[\mathrm{Co}(\mathrm{en})_{3}\right]^{3+}$ salts are very numerous and it is well established that different conformers are associated with different hydrogen bonding arrays of the bound amino groups. $\left[\mathrm{Co}(\mathrm{en})_{3}\right]^{3+}$ is, of course, unlike $\left[\mathrm{M}\left(R, S-\mathrm{Me}_{6} \text { cyclam }\right)\right]^{2+}(\mathrm{M}=\mathrm{Cu}, \mathrm{Ni})$ both in that it is coordinately saturated and that it has a greater number of NH sites with a greater number of possible orientations. In complex 3 , the $\Lambda-\left[\mathrm{Co}(\mathrm{en})_{3}\right]^{3+}$ has the $\delta, \delta, \lambda\left(\right.$ lel $\left._{2} O b\right)$ conformation and forms $\mathrm{NH} \cdots \mathrm{O}$ bonds to 
three different water molecules (probably involved in further hydrogen bond interactions, though their hydrogen atoms were not located) as well as to two uranyl oxo groups and two,

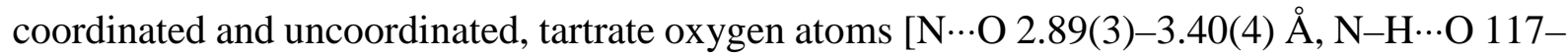
$160^{\circ}$ ]. In this way it serves to link into the third dimension the sheets of the $2 \mathrm{D}$ uranyl polymer. The hydroxyl anion forms an intra-sheet hydrogen bond with a carboxylate oxygen atom $\left[\mathrm{O} 25 \cdots \mathrm{O} 14^{\mathrm{k}} 2.76(2) \AA ̊ \AA, \mathrm{O} 25-\mathrm{H} \cdots \mathrm{O} 14^{\mathrm{k}} 151^{\circ}\right.$; symmetry code: $\left.\mathrm{k}=x-1 / 2,1 / 2-y, 1-z\right]$. The KPI, with solvent molecules excluded, amounts to 0.57 .

A return to $\operatorname{bis}\left(\kappa^{2} O, O^{\prime}\right)$ coordination of bridging camphorate is seen in the complex $\left[\mathrm{PPh}_{4}\right]\left[\mathrm{UO}_{2}(\mathrm{cam})\left(\mathrm{NO}_{3}\right)\right](4)$. The unique uranium atom is chelated by two carboxylate groups and one nitrate anion [U-O(oxo) $1.757(7)$ and $1.769(7) \AA$, U-O(carboxylate) 2.433(7)-

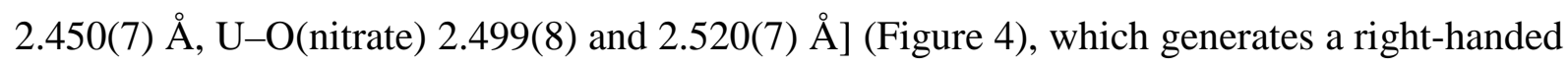
helical 1D polymer running parallel to the $b$ axis. These strands are arranged in sheets parallel to (001) and separated by layers of counterions. No parallel-displaced $\pi$-stacking interaction between $\mathrm{PPh}_{4}{ }^{+}$cations is present, and only one $\mathrm{CH} \cdots \pi$ interaction, involving a methyl proton of $\mathrm{cam}^{2-}$, is to be found $\left[\mathrm{H} \cdots\right.$ centroid $2.86 \AA$, C-H $\cdots$ centroid $\left.130^{\circ}\right]$. Each $\mathrm{PPh}_{4}{ }^{+}$cation is involved in a relatively small number of weak $\mathrm{CH} \cdots \mathrm{O}$ interactions beyond dispersion through only three of the four phenyl groups but these serve to link it to four separate polymer strands, thus creating a 3D network, albeit loosely connected. Complex 4 can thus be seen as a species where the conformational and coordinative preferences of the camphorate dianion have their greatest influence. With a KPI of 0.68 , the packing does not contain significant voids. 

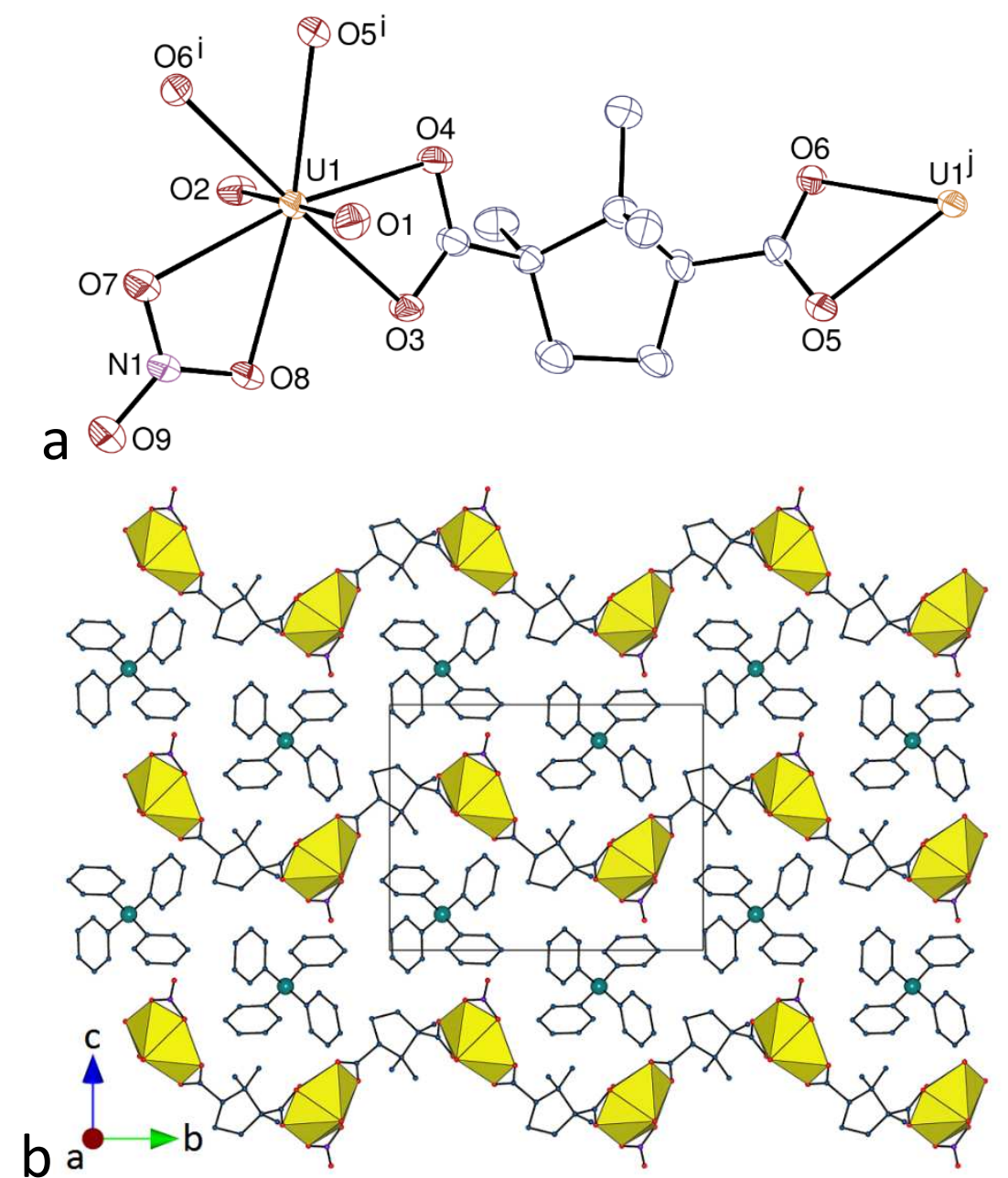

Figure 4. (a) View of compound 4. Displacement ellipsoids are drawn at the $30 \%$ probability level and counterions are omitted. Symmetry codes: $\mathrm{i}=2-x, y+1 / 2,1-z ; \mathrm{j}=2-x, y-1 / 2,1-z$. (b) View of the packing with chains viewed side-on. Hydrogen atoms are omitted in both views.

Complex 5, $\left[\mathrm{PPh}_{3} \mathrm{Me}_{3}\left[\mathrm{NH}_{4}\right]_{3}\left[\left(\mathrm{UO}_{2}\right)_{6}(\mathrm{cam})_{9}\right]\right.$, crystallizes in the hexagonal Sohncke space group $\mathrm{P6}_{3}$, the asymmetric unit containing two uranium atoms in general position, and three fully deprotonated, bis-chelating $\mathrm{cam}^{2-}$ ligands (Figure 5). Both uranium atoms are chelated by three carboxylate groups [U-O(oxo) 1.75(3)-1.77(2) A, U-O(carboxylate) 2.36(2)-2.51(3) $\mathrm{A}]$, but here the bridging nature of all ligands and their curved geometry result in the formation of a hexanuclear cage with threefold rotation symmetry. This cage differs from the octanuclear, pseudo-cubic species which is frequently found in uranyl camphorate complexes (Figure 6), ${ }^{22,23}$ and it is in fact the first hexanuclear uranyl carboxylate cage, the 

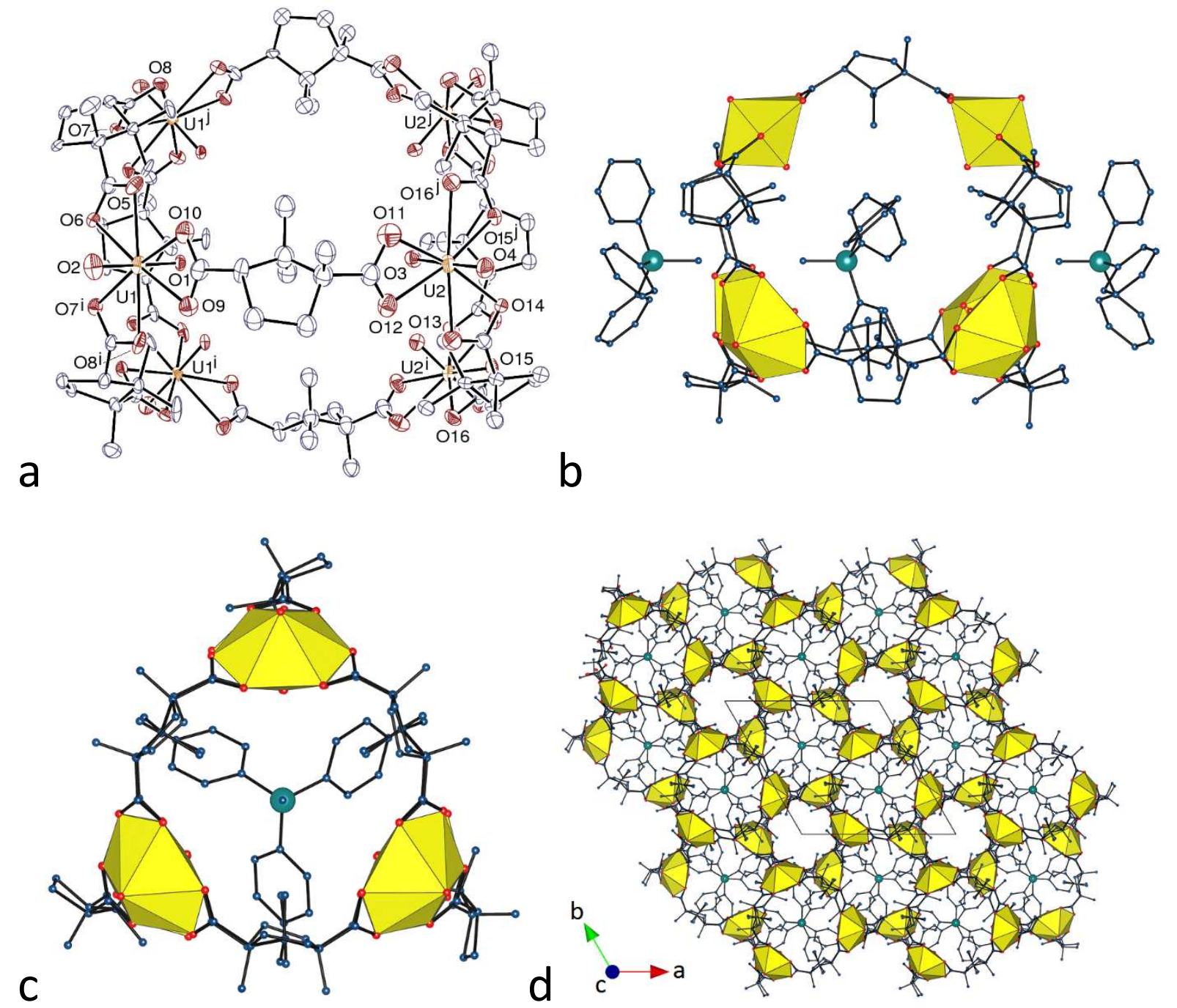

Figure 5. (a) View of compound 5. Displacement ellipsoids are drawn at the $10 \%$ probability level. Counterions and hydrogen atoms are omitted. Symmetry codes: $\mathrm{i}=1-y, x-y, z ; \mathrm{j}=y-x+1,1-x, z$. (b) View of the hexanuclear cage and the three associated $\mathrm{PPh}_{3} \mathrm{Me}^{+}$counterions. (c) The hexanuclear cage and the included $\mathrm{PPh}_{3} \mathrm{Me}^{+}$counterion viewed down the threefold rotation axis. (d) View of the packing. Hydrogen atoms and disordered ammonium ions are omitted.

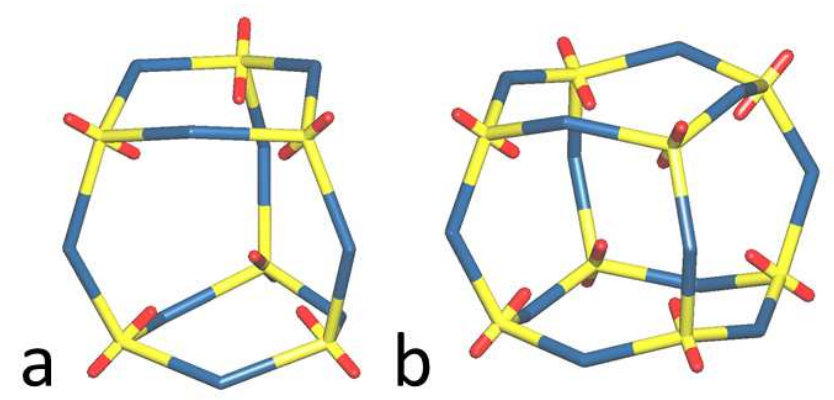

Figure 6. Simplified views of the hexanuclear cage in complex 5 (a) and the octanuclear cage in previous uranyl camphorate complexes (b). Yellow, uranium; red, oxygen; blue, camphorate ligand. 
previous examples being either dinuclear (helicate), ${ }^{36}$ tetranuclear, ${ }^{26,37-39}$ octanuclear, ${ }^{17,22,23,28,32,34,35}$ or even of higher nuclearity. ${ }^{32,35}$ The $\left[\left(\mathrm{UO}_{2}\right)_{6}(\mathrm{cam})_{9}\right]^{6-}$ moiety in $\mathbf{5}$ has $C_{3}$ point symmetry, but the uranium atoms alone define a trigonal prismatic motif of $D_{3 \mathrm{~h}}$ symmetry, which results in two sets of U...U distances, the shorter ones being within the trigonal bases [8.9093(18) and 9.012(3) ̊̊ for U1 and U2, respectively], and the longer ones being along the prism height $[9.5041(14) \AA]$. These distances are comparable to those in the octanuclear camphorate cages $[9.2606(8)-9.7845(7) \AA]$, and they are larger than those found in cages based on other polycarboxylates such as Kemp's triacid $[5.01-5.63 \AA],{ }^{34}$ cis-1,2cyclohexanedicarboxylate $[5.37-5.61 \AA],{ }^{17}$ or trans-1,2-cyclohexanedicarboxylate [5.82-6.95 $\AA{ }^{37,38}$ The dihedral angles between the two carboxylate groups in each ligand are 104(3), $107(4)$ and $108(3)^{\circ}$, somewhat smaller than in the octanuclear cages $\left[113.8(13)-119.3(13)^{\circ}\right]$. The dihedral angles between the equatorial planes of camphorate-bridged uranyl cations are 95.1(4) and $94.2(5)^{\circ}$ for the cations in the trigonal faces, and $103.0(5)^{\circ}$ for the cations pertaining to different faces; these values are also smaller that those in the larger cage [96.32(14)$\left.117.05(17)^{\circ}\right]$. All these differences in dihedral angles are in keeping with the smaller size and higher curvature of the cage in 5. The three well-ordered $\mathrm{PPh}_{3} \mathrm{Me}^{+}$counterions, all with threefold rotation symmetry, are in close association with the cage unit, two of them outside and with their methyl group pointing toward the prism basis centre, and one inside the cavity and with its phenyl rings directed towards the spaces between camphorate ligands (Figure 7). When viewed down the $c$ axis (Figure 5d), the packing displays two kinds of channels: those corresponding to the cage cavities and containing the $\mathrm{PPh}_{3} \mathrm{Me}^{+}$counterions, and those between cages and containing the ammonium cations generated in situ, which are highly disordered around threefold rotation axes (see Experimental Section), as well as probably disordered solvent molecules (the KPI with disordered ammonium cations excluded amounts to 0.58 ). The 
cages are arranged in sheets parallel to $\left(\begin{array}{ll}0 & 0\end{array}\right)$, which are separated from one another by layers of unincluded $\mathrm{PPh}_{3} \mathrm{Me}^{+}$counterions.
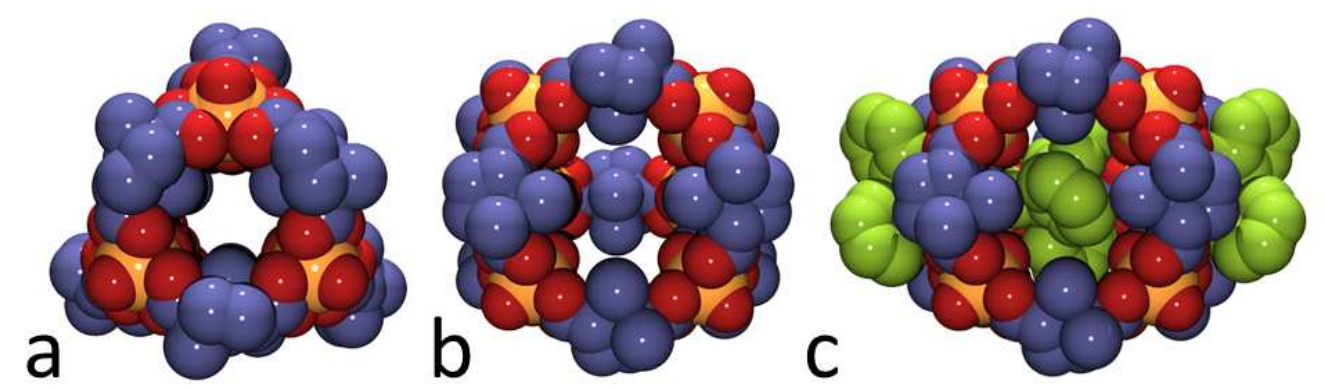

Figure 7. Spacefill representations of the cage in complex $\mathbf{5}$, viewed down the trigonal axis (a), sideways (b), and sideways with the included and two adjoining counterions in green (c). Yellow, uranium; red, oxygen; blue, carbon; hydrogen atoms are omitted.

Complex 5 provides another example where the presence of both ammonium and phosphonium cations in the lattice is associated with the crystallization of a closed oligomeric uranyl-containing polyanion, ${ }^{17,26}$ and the remarkable difference from complex $\mathbf{4}$ is probably due to the influence of this combination. In other cases where $\mathrm{PPh}_{4}^{+}$or $\mathrm{PPh}_{3} \mathrm{Me}^{+}$is the sole additional cation associated with an anionic uranyl species, relatively minor structural differences have been found. ${ }^{24}$ In contrast to the octanuclear cage in $\left[\mathrm{NH}_{4}\right]\left[\mathrm{PPh}_{4}\right]\left[\left(\mathrm{UO}_{2}\right)_{8}(c-1,2-\right.$ chdc $\left.)_{9}\left(\mathrm{H}_{2} \mathrm{O}\right)_{6}\right] \cdot 3 \mathrm{H}_{2} \mathrm{O}(c-1,2$-chdc $=$ cis-1,2-cyclohexanedicarboxylate $),{ }^{17}$ where ammonium ion is included, it is the much larger $\mathrm{PPh}_{3} \mathrm{Me}^{+}$ion that is included in the hexanuclear cage here. The exact role of ammonium ions in the lattice is unclear due to their disorder and lack of hydrogen atom locations but all lie at points compatible with $\mathrm{NH} \cdots \mathrm{O}$ interactions involving carboxylate oxygen atoms $[\mathrm{N} \cdots \mathrm{O} 2.81(4)-2.97(6) \AA]$ and thus appear to have a role in the assembly. The form of the cages is compatible with the threefold symmetry of the included $\mathrm{PPh}_{3} \mathrm{Me}^{+}$cation in that the $C_{3}$ axes are collinear, and the Hirshfeld surface for the cation indicates a single $\mathrm{CH} \cdots \mathrm{O}$ interaction beyond dispersion of each phenyl ring with a uranyl oxo group directed toward the interior of the cage $\left[\mathrm{C} \cdots \mathrm{O} 3.57(2) \AA, \mathrm{H} \cdots \mathrm{O} 2.62 \AA, \mathrm{C}-\mathrm{H} \cdots \mathrm{O} 174^{\circ}\right]$. The chirality of the cage has 
an influence in that the included cation has a chiral conformation, being that of a right-handed helix. This influence extends to the other two inequivalent $\mathrm{PPh}_{3} \mathrm{Me}^{+}$cations which are poised above the trigonal faces of the cage in that they adopt chiral conformations but these are opposite, so that the cations containing P1 (included) and P2 are of the same chirality and enantiomeric to that containing P3. Because of this, the sheets of unincluded cations that lie between those formed by the cages are racemic, since they include both P2- and P3-containing counterions. These unincluded cations appear to be involved in triple $\mathrm{CH} \cdots \mathrm{O}$ interactions with carboxylate oxygen atoms bound to uranyl $[\mathrm{C} \cdots \mathrm{O} 3.42(2)$ and 3.47(3) $\AA$, $\mathrm{H} \cdots \mathrm{O} 2.55$ and 2.62 $\AA$, C-H $\cdots \mathrm{O} 152$ and $149^{\circ}$ ], but there is no evidence of "embrace" interactions ${ }^{60}$ beyond dispersion within their sheets.

Luminescence properties. Emission spectra under excitation at $420 \mathrm{~nm}$ were recorded for complexes 1, $\mathbf{4}$ and $\mathbf{5}$ in the solid state (Figure 8), the other compounds being unavailable in sufficient quantity and purity. Whereas complex $\mathbf{5}$ is non-luminescent, both $\mathbf{1}$ and $\mathbf{4}$ display the usual fine structure associated with the vibronic progression corresponding to the $S_{11} \rightarrow S_{00}$ and $S_{10} \rightarrow S_{0 v}(v=0-4)$ electronic transitions, ${ }^{61}$ although emission in 4 is more intense than in $\mathbf{1}$, and its spectrum better resolved. Uranyl emission in $\mathbf{1}$ may be partially quenched due to the presence of copper(II) cations, as frequently observed. ${ }^{62}$ The main maxima in the spectrum of 4 are at $465,483,503,524,548$ and $574 \mathrm{~nm}$, the four well-resolved maxima in the spectrum of 1 being blue-shifted by about $2 \mathrm{~nm}$ with respect to their counterparts in 4 . These positions match those generally found for hexacoordinated uranyl species. ${ }^{63}$ 


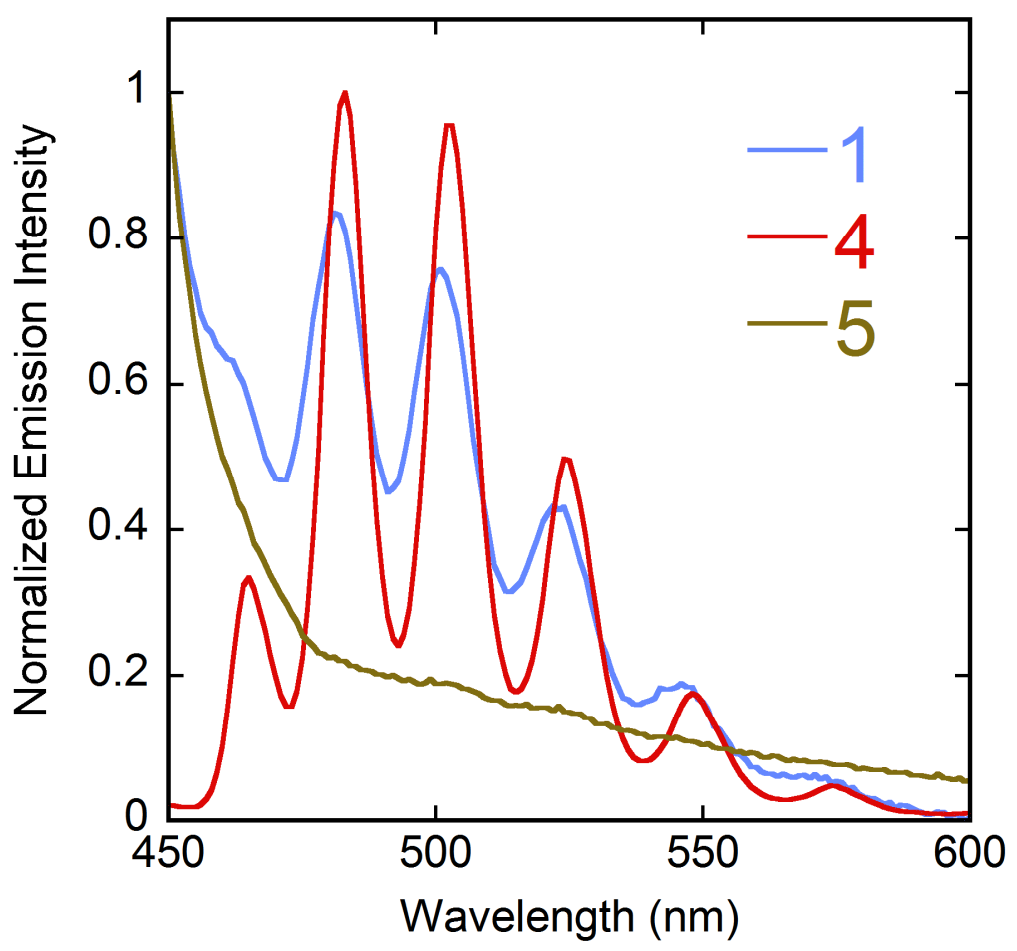

Figure 8. Emission spectra of compounds 1, 4 and $\mathbf{5}$ in the solid state at room temperature, under excitation at a wavelength of $420 \mathrm{~nm}$.

Solid-state photoluminescence quantum yields (PLQYs) of 2 and 23\% (with a standard deviation of ca. $\pm 2.5 \%$ ) have been measured for complexes $\mathbf{1}$ and $\mathbf{4}$, respectively. The low value for compound 1, possibly due to partial quenching by copper(II), is comparable to values recently found in a series of uranyl complexes with aliphatic $\alpha, \omega$-dicarboxylates. ${ }^{41}$ Both $\left[\mathrm{Cu}\left(R, S-\mathrm{Me}_{6} \mathrm{cyclam}\right)\right]^{2+}$ and $\left[\mathrm{Ni}\left(R, S-\mathrm{Me}_{6} \mathrm{cyclam}\right)\right]^{2+}$ have absorptions in the visible region ${ }^{64}$ which overlap with that of $\left[\mathrm{UO}_{2}\left(\mathrm{H}_{2} \mathrm{O}\right)_{5}\right]^{2+},{ }^{65}$ and which also overlap with the uranyl emission bands, so that the effect of $\left[\mathrm{Cu}\left(R, S-\mathrm{Me}_{6} \text { cyclam }\right)\right]^{2+}$ in complex 1 may be due to both preferential absorption of the incident light as well as energy transfer from any excited uranyl centres to the complex cations (a similar effect can be expected for compound $\mathbf{2}$, for which no spectrum could be recorded). While this argument is based on solution spectroscopic data, it is known that the solid state spectra of the $\mathrm{Ni}^{\mathrm{II}}$ and $\mathrm{Cu}^{\mathrm{II}}$ complexes of unfunctionalised cyclam closely match those in solution. ${ }^{66}$ The PLQY for complex 4 is similar to that of $24 \%$ we have measured under 
the same conditions for uranyl nitrate hexahydrate, and is one of the largest measured up to now in the family of uranyl carboxylate complexes, to be compared for example with $13 \%$ for $\left[\mathrm{PPh}_{4}\right]_{2}\left[\left(\mathrm{UO}_{2}\right)_{2}(t-1,4-\mathrm{chdc})_{3}\right] \cdot 4 \mathrm{H}_{2} \mathrm{O}\left(t-1,4-\mathrm{chdcH}_{2}=\right.$ trans-1,4-cyclohexanedicarboxylic acid $),{ }^{24}$ $12 \%$ for $\left[\mathrm{PPh}_{4}\right]\left[\mathrm{UO}_{2}(\mathrm{C} 6)\left(\mathrm{NO}_{3}\right)\right] \quad\left(\mathrm{H}_{2} \mathrm{C} 6=\right.$ adipic acid $),{ }^{41}$ and $9 \%$ for $\left[\mathrm{H}_{2} \mathrm{NMe}_{2}\right]\left[\mathrm{PPh}_{3} \mathrm{Me}\right]\left[\left(\mathrm{UO}_{2}\right)_{2}(\mathrm{ADA})_{3}\right] \cdot \mathrm{H}_{2} \mathrm{O} \quad\left(\mathrm{H}_{2} \mathrm{ADA} \quad=\quad 1,3\right.$-adamantanediacetic $\quad{ }$ acid $) .{ }^{26}$ However, larger PLQYs are known, such as $42 \%$ measured for the previously described $\mathrm{Rb}_{2}\left[\mathrm{UO}_{2}(\text { dipic })_{2}\right]($ dipic $=$ dipicolinate $),{ }^{3} 49 \%$ for $\left[\mathrm{NMe}_{4}\right]_{2}\left[\left(\mathrm{UO}_{2}\right)_{4}\left(\mathrm{C}_{2} \mathrm{O}_{4}\right)_{4}(\mathrm{C} 4)\right]\left(\mathrm{H}_{2} \mathrm{C} 4=\right.$ succinic acid), ${ }^{67}$ and $58 \%$ for $\left[\mathrm{UO}_{2}(\mathrm{HL})\left(\mathrm{H}_{2} \mathrm{O}\right)\right]\left(\mathrm{H}_{3} \mathrm{~L}=\right.$ benzene-1,3,5-tricarboxylic acid $) .{ }^{68} \mathrm{We}$ have discussed elsewhere ${ }^{41}$ the possibility that energy transfer between close uranyl centres might prolong excited state lifetimes and thus that $\mathrm{U} \cdots \mathrm{U}$ separations within lattices may be important criteria in relation to PLQY values but the shortest $U \cdots$ U distance does not seem to be a relevant parameter in the case of complex 4 since, at 8.0460(3) $\AA$ (interchain), it is indeed larger than the values measured in the two most strongly emitting complexes cited above (5.511 and $5.232 \AA$, respectively), but comparable to distances in some much more weakly emitting species. ${ }^{41}$ We have also considered that phosphonium cations may act as quenching centres and thus that U...P separations may be significant but the shortest U..P distance in $4,6.750(3) \AA$, is within the range found in a series of complexes with smaller PLQYs,${ }^{41}$ which suggests that this is not the dominant factor here. This also appears to be the case for the non-emissive complex

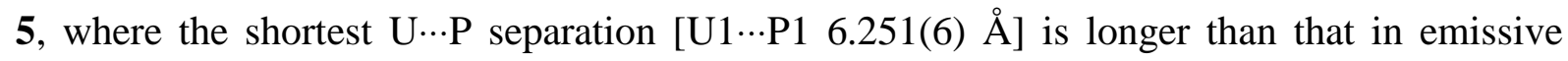
relatives. $^{41}$

\section{CONCLUSIONS}

We have reported here the synthesis and crystal structure of five uranyl camphorate complexes including five different bulky counterions, as well as the luminescence properties of three of them. Three of the counterions are $3 \mathrm{~d}$ block metal ion complexes, $\left[\mathrm{M}\left(R, S-\mathrm{Me}_{6} \mathrm{cyclam}\right)\right]^{2+}(\mathrm{M}=$ 
$\mathrm{Cu}, \mathrm{Ni}$, which have been previoulsy used in association with cis- and trans-1,2cyclohexanedicarboxylate, and aliphatic $\alpha, \omega$-dicarboxylate ligands, ${ }^{25,41}$ and $\left[\mathrm{Co}(\mathrm{en})_{3}\right]^{3+}$, for which only one example of use as a counterion for an anionic uranyl pimelate complex is known. ${ }^{69}$ The camphorate complexes with these counterions are either discrete, 1D or 2D, respectively, the last having $R, R$-tartrate coligands, and its lattice thus containing three enantiomerically pure chiral species. The fact that a change in interaction energy as small as 10 $\mathrm{kJ} \mathrm{mol}^{-1}$ is sufficient to change an equilibrium constant such as a solubility product by a factor of 100 is an obvious explanation of the variability observed in our efforts to systematically explore the effect of heterocations on the nature of crystalline uranyl ion complexes. In just the present examples, the balance between coordinative and hydrogen bonding interactions of $\left[\mathrm{M}\left(R, S-\mathrm{Me}_{6} \text { cyclam }\right)\right]^{2+}$ complexes is clearly rather delicate and while the use of $\left[\mathrm{Co}(\mathrm{en})_{3}\right]^{3+}$ eliminates the competition of coordination, the hydrogen bonding sites on this cation appear to be of more restricted access than those of the macrocycle complexes and to favour in this case interactions with small species such as water molecules rather than direct interaction with carboxylate groups.

The other two cations used are $\mathrm{PPh}_{4}{ }^{+}$and $\mathrm{PPh}_{3} \mathrm{Me}^{+}$, the latter associated with $\mathrm{NH}_{4}{ }^{+}$ counterions formed in situ. While the complex with $\mathrm{PPh}_{4}{ }^{+}$counterions is a 1D coordination polymer (with nitrate coligands), the complex with $\mathrm{PPh}_{3} \mathrm{Me}^{+} / \mathrm{NH}_{4}{ }^{+}$is a discrete, anionic hexanuclear cage, different from the octanuclear uranyl camphorate species previously described, ${ }^{22,23}$ thus providing an example in which the size of the cage can be modulated through variation of the structure-directing counterions. That the combination of ammonium and phosphonium cations seems to favour the formation of closed uranyl dicarboxylate oligomers, as observed here and in previous work with different carboxylates, ${ }^{17,26}$ is encouraging, especially given that in the present case it leads to inclusion of a relatively large cation, $\mathrm{PPh}_{3} \mathrm{Me}^{+}\left(\mathrm{NH}_{4}{ }^{+}\right.$only was found to be included in one of the previously reported cages $\left.{ }^{17}\right)$, 
but the number of known structures is still too small to be sure of ways to exploit this combination. This complex belongs to the yet somewhat restricted family of uranyl-organic cage compounds, with the added benefit from the use of the $(1 R, 3 S)-(+)$-camphorate ligand that the cage formed is chiral and enantiomerically pure. It is disappointing, however, to find that this complex is non-emissive, a somewhat surprising observation given that such a degree of quenching has not been found in other uranyl ion complexes involving phosphonium countercations, ${ }^{24,41}$ although none of these have involved inclusion of the cation in a cage.

\section{ASSOCIATED CONTENT}

\section{Accession Codes}

CCDC 1874636-1874640 contain the supplementary crystallographic data for this paper. These data can be obtained free of charge via www.ccdc.cam.ac.uk/data_request/cif, or by emailing data_request@ccdc.cam.ac.uk, or by contacting The Cambridge Crystallographic Data Centre, 12 Union Road, Cambridge CB2 1EZ, UK; fax: +44 1223336033.

\section{AUTHOR INFORMATION}

\section{Corresponding Authors}

*E-mail: pierre.thuery@ cea.fr. (P.T.)

*E-mail: harrowfield@unistra.fr. (J.H.)

\section{ORCID}

Pierre Thuéry: 0000-0003-1683-570X

Youssef Atoini: 0000-0003-4851-3713

Jack Harrowfield: 0000-0003-4005-740X

\section{Notes}

The authors declare no competing financial interest. 


\section{REFERENCES}

1. Tranchemontagne, D. J.; Ni, Z.; O’Keeffe, M.; Yaghi, O. M. Reticular Chemistry of MetalOrganic Polyhedra. Angew. Chem. Int. Ed. 2008, 47, 5136-5147.

2. Young, N. J.; Hay, B. P., Structural Design Principles for Self-Assembled Coordination Polygons and Polyhedra. Chem. Commun. 2013, 49, 1354-1379.

3. Harrowfield, J. M.; Lugan, N.; Shahverdizadeh, G. H.; Soudi, A. A.; Thuéry, P. Solid State Luminescence and $\pi$-Stacking in Crystalline Uranyl Dipicolinates. Eur. J. Inorg. Chem. 2006, 389-396 and references therein.

4. Wang, K. X.; Chen, J. S. Extended Structures and Physicochemical Properties of UranylOrganic Compounds. Acc. Chem. Res. 2011, 44, 531-540.

5. Li, X. Q.; Zhang, H. B.; Wu, S. T.; Lin, J. D.; Lin, P.; Li, Z. H.; Du, S. W. Synthesis, Structures and Luminescent Properties of New $\mathrm{Pb}(\mathrm{II}) / \mathrm{M}(\mathrm{I})(\mathrm{M}=\mathrm{K}, \mathrm{Rb}$ and $\mathrm{Cs})$ Frameworks Based on Dicarboxylic Acids: a Novel Icosahedral Pb6-M6 SBU. CrystEng Comm 2012, 14, 936-944.

6. Andrews, M. B.; Cahill, C. L. Uranyl Bearing Hybrid Materials: Synthesis, Speciation, and Solid-State Structures. Chem. Rev. 2013, 113, 1121-1136.

7. Ahmad, N.; Chughtai, A. H.; Younus, H. A.; Verpoort, F. Discrete Metal-Carboxylate SelfAssembled Cages: Design, Synthesis and Applications, Coord. Chem. Rev. 2014, 280, 1-27.

8. Loiseau, T.; Mihalcea, I.; Henry, N.; Volkringer, C. The Crystal Chemistry of Uranium Carboxylates. Coord. Chem. Rev. 2014, 266-267, 69-109.

9. Su, J.; Chen, J. S. MOFs of Uranium and the Actinides. Struct. Bond. 2015, 163, 265-296.

10. Thuéry, P.; Harrowfield, J. Structural Variations in the Uranyl/4,4'-Biphenyldicarboxylate System. Rare Examples of 2D $\rightarrow$ 3D Polycatenated Uranyl-Organic Networks. Inorg. Chem. 2015, 54, 8093-8102 and references therein. 
11. Thuéry, P.; Harrowfield, J. Uranyl Ion Complexes with Long-Chain Aliphatic $\alpha, \omega-$ Dicarboxylates and 3d-Block Metal Counterions. Inorg. Chem. 2016, 55, 2133-2145 and references therein.

12. Jayasinghe, A. S.; Payne, M. K.; Forbes, T. Z., Synthesis and Characterization of Heterometallic Uranyl Pyridinedicarboxylate Compounds. J. Solid State Chem. 2017, 254, 2531.

13. Thuéry, P.; Harrowfield, J. Recent Advances in Structural Studies of Heterometallic UranylContaining Coordination Polymers and Polynuclear Closed Species. Dalton Trans. 2017, 46, 13660-13667.

14. Rusanova, J. A.; Rusanov, E. B.; Domasevitch, K. V. A New Adamantanecarboxylate Coordination Polymer: Poly[[( $\mu_{3}$-Adamantane-1,3-dicarboxylato)aquadioxidouranium(VI)] monohydate]. Acta Cryst., Sect. C 2010, 66, m207-m210.

15. Thuéry, P.; Rivière, E.; Harrowfield, J. Uranyl and Uranyl-3d Block Cation Complexes with 1,3-Adamantanedicarboxylate: Crystal Structures, Luminescence and Magnetic Properties. Inorg. Chem. 2015, 54, 2838-2850.

16. Thuéry, P.; Atoini, Y.; Harrowfield, J. Crown Ethers and Their Alkali Metal Ion Complexes as Assembler Groups in Uranyl-Organic Coordination Polymers with cis-1,3-, cis-1,2-, and trans-1,2-Cyclohexanedicarboxylates. Cryst. Growth Des. 2018, 18, 3167-3177.

17. Thuéry, P.; Atoini, Y.; Harrowfield, J. Counterion-Controlled Formation of an Octanuclear Uranyl Cage with cis-1,2-Cyclohexanedicarboxylate Ligands. Inorg. Chem. 2018, 57, 62836288.

18. Gu, Z. G.; Zhan, C.; Zhang, J.; Bu, X. Chiral Chemistry of Metal-Camphorate Frameworks. Chem. Soc. Rev. 2016, 45, 3122-3144.

19. Kumaradhas, P.; Levendis, D. C.; Koritsanszky, T., The Low-Temperature Study of D- and DL-Camphoric Anhydride. Acta Crystallogr., Sect. C 2000, 56, e103-e104. 
20. Groom, C. R.; Bruno, I. J.; Lightfoot, M. P.; Ward, S. C. The Cambridge Structural Database. Acta Crystallogr., Sect. B 2016, 72, 171-179.

21. Thuéry, P. Solvothermal Synthesis and Crystal Structure of Uranyl Complexes with 1,1Cyclobutanedicarboxylic and $(1 R, 3 S)-(+)$-Camphoric Acids - Novel Chiral Uranyl-Organic Frameworks. Eur. J. Inorg. Chem. 2006, 3646-3651.

22. Thuéry, P. A Nanosized Uranyl Camphorate Cage and its Use as a Building Unit in a MetalOrganic Framework. Cryst. Growth Des. 2009, 9, 4592-4594.

23. Thuéry, P.; Harrowfield, J. Chiral One- to Three-Dimensional Uranyl-Organic Assemblies from (1R,3S)-(+)-Camphoric Acid. CrystEngComm 2014, 16, 2996-3004.

24. Thuéry, P.; Atoini, Y.; Harrowfield, J. Uranyl-Organic Coordination Polymers with trans1,2-, trans-1,4-, and cis-1,4-Cyclohexanedicarboxylates: Effects of Bulky $\mathrm{PPh}_{4}{ }^{+}$and $\mathrm{PPh}_{3} \mathrm{Me}^{+}$ Counterions. Cryst. Growth Des. 2018, 18, 2609-2619.

25. Thuéry, P.; Harrowfield, J. $[\mathrm{Ni}(\text { cyclam })]^{2+}$ and $\left[\mathrm{Ni}\left(R, S-\mathrm{Me}_{6} \text { cyclam }\right)\right]^{2+}$ as Linkers or Counterions In Uranyl-Organic Species with cis- and trans-1,2-Cyclohexanedicarboxylate Ligands. Cryst. Growth Des. 2018, 18, 5512-5520.

26. Thuéry, P.; Atoini, Y.; Harrowfield, J. Closed Uranyl-Dicarboxylate Oligomers: A Tetranuclear Metallatricycle with Uranyl Bridgeheads and 1,3-Adamantanediacetate Linkers. Inorg. Chem. 2018, 57, 7932-7939.

27. Hickam, S.; Burns, P. C. Oxo Clusters of $5 f$ Elements. Struct. Bonding (Berlin, Ger.) 2017, $173,121-154$ and references therein.

28. Thuéry, P.; Nierlich, M.; Baldwin, B. W.; Komatsuzaki, N.; Hirose, T. A Metal-Organic Molecular Box Obtained from Self-Assembling around Uranyl Ions. J. Chem. Soc., Dalton Trans., 1999, 1047-1048.

29. Thuéry, P.; Masci, B. Self-Assembly of an Octa-Uranate Cage Complex with a Rigid bisCatechol Ligand. Supramol. Chem. 2003, 15, 95-99. 
30. Thuéry, P.; Villiers, C.; Jaud, J.; Ephritikhine, M.; Masci, B. Uranyl-Based Metallamacrocycles: Tri- and Tetranuclear Complexes with $(2 R, 3 R, 4 S, 5 S)$ Tetrahydrofurantetracarboxylic Acid. J. Am. Chem. Soc. 2004, 126, 6838-6839.

31. Charushnikova, I. A.; Grigor'ev, M. S.; Krot, N. N. Synthesis and Crystal Structure of New $\mathrm{U}(\mathrm{VI})$ and $\mathrm{Np}(\mathrm{VI})$ Benzoates, $\mathrm{K}_{11}\left(\mathrm{AnO}_{2}\right)_{23}\left(\mathrm{OOCC}_{6} \mathrm{H}_{5}\right)_{57}\left(\mathrm{H}_{2} \mathrm{O}\right)_{18+x}$. Radiochemistry 2010, 52, $138-144$.

32. Pasquale, S.; Sattin, S.; Escudero-Adán, E. C.; Martínez-Belmonte, M.; de Mendoza, J. Giant Regular Polyhedra from Calixarene Carboxylates and Uranyl. Nature Commun. 2012, 3, 785791.

33. Unruh, D. K.; Gojdas, K.; Libo, A.; Forbes, T. Z. Development of Metal-Organic Nanotubes Exhibiting Low-Temperature, Reversible Exchange of Confined "Ice Channels". J. Am. Chem. Soc. 2013, 135, 7398-7401.

34. Thuéry, P. A Highly Adjustable Coordination System: Nanotubular and Molecular Cage Species in Uranyl Ion Complexes with Kemp's Triacid. Cryst. Growth Des. 2014, 14, 901-904. 35. Thuéry, P. Increasing Complexity in the Uranyl Ion-Kemp's Triacid System: From One- and Two-Dimensional Polymers to Uranyl-Copper(II) Dodeca- and Hexadecanuclear Species. Cryst. Growth Des. 2014, 14, 2665-2676.

36. Thuéry, P.; Harrowfield, J. A New Form of Triple-Stranded Helicate Found in Uranyl Complexes of Aliphatic $\alpha, \omega$-Dicarboxylates. Inorg. Chem. 2015, 54, 10539-10541.

37. Thuéry, P.; Harrowfield, J. Coordination Polymers and Cage-Containing Frameworks in Uranyl Ion Complexes with rac- and (1R,2R)-trans-1,2-Cyclohexanedicarboxylates: Consequences of Chirality. Inorg. Chem. 2017, 56, 1455-1469.

38. Thuéry, P.; Harrowfield, J. Tetrahedral and Cuboidal Clusters in Complexes of Uranyl and Alkali or Alkaline-Earth Metal Ions with rac- and (1R,2R)-trans-1,2Cyclohexanedicarboxylate. Cryst. Growth Des. 2017, 17, 2881-2892. 
39. Lee, J.; Brewster, J. T., II; Song, B.; Lynch, V. M.; Hwang, I.; Li, X.; Sessler, J. L. Uranyl Dication Mediated Photoswitching of a Calix[4]pyrrole-Based Metal Coordination Cage. Chem. Commun. 2018, 54, 9422-9425.

40. Tait, A. M.; Busch, D. H., in Inorganic Syntheses, Vol. 18; Douglas, B. E., (Vol. Ed.); John Wiley \& Sons: New York, 1978; Chapter 1.2, p. 10.

41. Thuéry, P.; Atoini, Y.; Harrowfield, J. Structure-Directing Effects of Counterions in Uranyl Ion Complexes with Long-Chain Aliphatic $\alpha, \omega$-Dicarboxylates: 1D to Polycatenated 3D Species. Submitted.

42. Werner, A. Zur Kenntnis des Asymmetrischen Kobaltatoms. V. Chem. Ber. 1912, 45, 121130.

43. Broomhead, J. A.; Dwyer, F. P.; Hogarth, J. W. Resolution of the Tris(Ethylenediamine)Cobalt(III) Ion. Inorganic Syntheses. 1960, VI, 183-186.

44. Hooft, R. W. W. COLLECT, Nonius BV: Delft, The Netherlands, 1998.

45. Otwinowski, Z.; Minor, W. Processing of X-Ray Diffraction Data Collected in Oscillation Mode. Methods Enzymol. 1997, 276, 307-326.

46. Sheldrick, G. M. SHELXT - Integrated Space-Group and Crystal-Structure Determination. Acta Crystallogr., Sect. A 2015, 71, 3-8.

47. Sheldrick, G. M. Crystal Structure Refinement with SHELXL. Acta Crystallogr., Sect. C 2015, $71,3-8$.

48. Spek, A. L. PLATON SQUEEZE: a Tool for the Calculation of the Disordered Solvent Contribution to the Calculated Structure Factors. Acta Crystallogr., Sect. C 2015, 71, 9-18.

49. Farrugia, L. J. WinGX and ORTEP for Windows: an Update. J. Appl. Crystallogr. 2012, 45, $849-854$.

50. Momma, K.; Izumi, F. VESTA: a Three-Dimensional Visualization System for Electronic and Structural Analysis. J. Appl. Crystallogr. 2008, 41, 653-658. 
51. Blatov, V. A. TOPOS; Samara State University: Samara, Russia, 2004.

52. Thuéry, P.; Harrowfield, J. $\mathrm{Ag}^{\mathrm{I}}$ and $\mathrm{Pb}^{\mathrm{II}}$ as Additional Assembling Cations in Uranyl Coordination Polymers and Frameworks. Cryst. Growth Des. 2017, 17, 2116-2130 and references therein.

53. Spackman, M. A.; Jayatilaka, D. Hirshfeld Surface Analysis. CrystEngComm 2009, 11, 1932.

54. Wolff, S. K.; Grimwood, D. J.; McKinnon, J. J.; Turner, M. J.; Jayatilaka, D.; Spackman, M. A. CrystalExplorer; University of Western Australia: Crawley, Australia, 2012.

55. Taylor, R.; Kennard, O. Crystallographic Evidence for the Existence of C-H $\cdots \mathrm{O}, \mathrm{C}-\mathrm{H} \cdots \mathrm{N}$, and C-H $\cdots \mathrm{Cl}$ Hydrogen Bonds. J. Am. Chem. Soc. 1982, 104, 5063-5070.

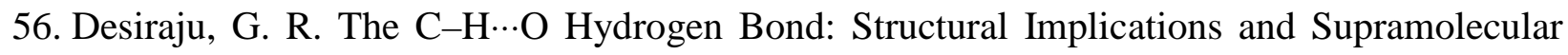
Design. Acc. Chem. Res. 1996, 29, 441-449.

57. Spek, A. L. Structure Validation in Chemical Crystallography. Acta Crystallogr., Sect. D 2009, $65,148-155$.

58. Thuéry, P. Reaction of Uranyl Nitrate with Carboxylic Diacids under Hydrothermal Conditions. Crystal Structure of Complexes with L(+)-Tartaric and Oxalic Acids. Polyhedron 2007, 26, 101-106.

59. Thuéry, P.; Harrowfield, J. Uranyl Ion Complexes with Chiral Malic and Citramalic, and Prochiral Citric and Tricarballylic Acids: Influence of Coligands and Additional Metal Cations. Eur. J. Inorg. Chem. 2018, 1016-1027 and references therein.

60. Scudder, M.; Dance, I. Crystal Supramolecular Motifs. Two- and Three-Dimensional Networks of $\mathrm{Ph}_{4} \mathrm{P}^{+}$Cations Engaged in Sixfold Phenyl Embraces. J. Chem. Soc., Dalton Trans 1998, 3167-3175, and references therein. 
61. Brachmann, A.; Geipel, G.; Bernhard, G.; Nitsche, H. Study of Uranyl(VI) Malonate Complexation by Time Resolved Laser-Induced Fluorescence Spectroscopy (TRLFS). Radiochim. Acta 2002, 90, 147-153.

62. Kerr, A. T.; Cahill, C. L. Postsynthetic Rearrangement/Metalation as a Route to Bimetallic Uranyl Coordination Polymers: Syntheses, Structures, and Luminescence. Cryst. Growth Des. 2014, 14, 1914-1921.

63. Thuéry, P.; Harrowfield, J. Structural Consequences of 1,4-Cyclohexanedicarboxylate Cis/Trans Isomerism in Uranyl Ion Complexes: From Molecular Species to 2D and 3D Entangled Nets. Inorg. Chem. 2017, 56, 13464-13481 and references therein.

64. Curtis, N. F. Some Cyclic Tetra-Amines and their Metal-Ion Complexes. Part I. Two Isomeric Hexamethyltetra-azacyclotetradecanes and their Copper(II) and Nickel(II) Complexes. J. Chem. Soc. 1964, 2644-2650.

65. Burrows, H. D.; da Graça Miguel, M. Applications and Limitations of Uranyl Ion as a Photophysical Probe. Adv. Colloid Interf. Sci. 2001, 89-90, 485-496 and references therein.

66. Makowska-Janusik, M.; Kassiba, A.; Errien, N.; Mehdi, A. Mesoporous Silica Functionalized by Cyclam-Metal Groups: Spectroscopic Studies and Numerical Modeling. J. Inorg. Organomet. Polym. Mater. 2010, 20, 761-773.

67. Xie, J.; Wang, Y.; Liu, W.; Lin, X.; Chen, L.; Zou, Y.; Diwu, J.; Chai, Z.; Albrecht-Schmitt, T. E.; Liu, G.; Wang, S. Highly Sensitive Detection of Ionizing Radiations by a Photoluminescent Uranyl Organic Framework. Angew. Chem. Int. Ed. 2017, 56, 7500-7504. 68. Wang, Y.; Yin, X.; Liu, W.; Xie, J.; Chen, J.; Silver, M. A.; Sheng, D.; Chen, L.; Diwu, J.; Liu, N.; Chai, Z.; Albrecht-Schmitt, T. E.; Wang, S. Emergence of Uranium as a Distinct Metal Center for Building Intrinsic X-ray Scintillators. Angew. Chem. Int. Ed. 2018, 57, 7883-7887.

69. Thuéry, P.; Rivière, E.; Harrowfield, J. Counterion-Induced Variations in the Dimensionality and Topology of Uranyl Pimelate Complexes. Cryst. Growth Des. 2016, 16, 2826-2835. 


\section{Chiral Discrete and Polymeric Uranyl Ion Complexes with}

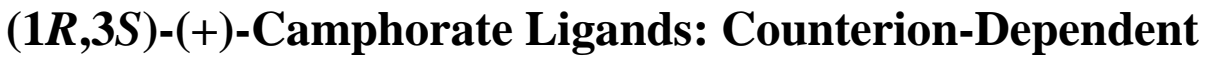 Formation of a Hexanuclear Cage}

Pierre Thuéry, Youssef Atoini and Jack Harrowfield

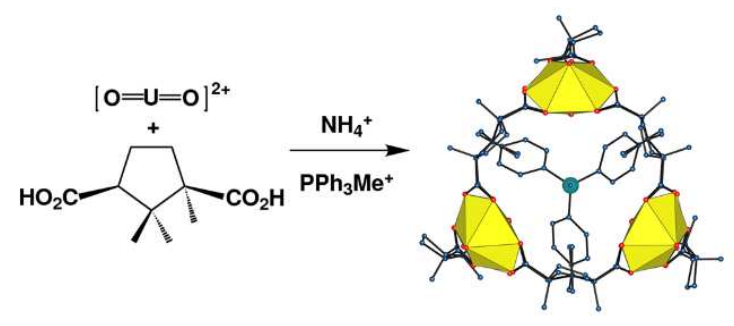

Five uranyl ion complexes with $(1 R, 3 S)-(+)$-camphorate ligands incorporating diverse bulky counterions were synthesized. While four of the complexes crystallize as OD (mononuclear), $1 \mathrm{D}$ and $2 \mathrm{D}$ species, the complex with $\mathrm{PPh}_{3} \mathrm{Me}^{+}$and $\mathrm{NH}_{4}{ }^{+}$counterions is a homochiral and homoleptic hexanuclear cage with a cavity of sufficient size for inclusion of one phosphonium cation. 